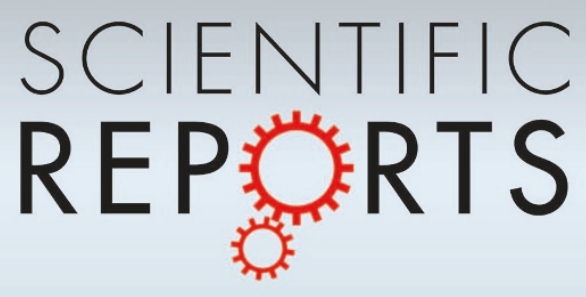

\title{
OPEN Microglia trigger astrocyte-mediated \\ MICROGLIA \\ neuroprotection via purinergic gliotransmission
}

SUBJECT AREAS:

CELL DEATH IN THE NERVOUS

SYSTEM

ASTROCYTE

INTERLEUKINS

\author{
Youichi Shinozaki ${ }^{1,2}$, Masatoshi Nomura $^{3}$, Ken Iwatsuki ${ }^{4}$, Yoshinori Moriyama ${ }^{5}$, Christian Gachet ${ }^{6}$ \\ \& Schuichi Koizumi ${ }^{1,2}$
}

Received

2 January 2014

'Department of Neuropharmacology, Interdisciplinary Graduate School of Medicine and Engineering, University of Yamanashi, 1110 Shimokato, Chuo, Yamanashi 409-3898, Japan, ${ }^{2} J a p a n$ Science and Technology Agency, CREST, Tokyo 102-0076, Japan, ${ }^{3}$ Department of Endocrine and Metabolic Diseases/Diabetes Mellitus Kyushu University Hospital, Fukuoka 812-8582, Japan, ${ }^{4}$ Institute for Innovation, Ajinomoto Co. Inc., Kawasaki $210-8681$, Japan, ${ }^{5}$ Advanced Science Research Center, Okayama University, Okayama 700-8530, Japan, Institut National de la Santé et de la Recherche Médicale (INSERM), U. 311 , Etablissement de Transfusion Sanguine, 10, rue Spielmann, B.P. 36, 67065 Strasbourg, France.

21 February 2014

Published

10 March 2014

Correspondence and requests for materials should be addressed to S.K. (skoizumi@ yamanashi.ac.jp)

Microglia are highly sensitive to even small changes in the brain environment, such as invasion of non-hazardous toxicants or the presymptomatic state of diseases. However, the physiological or pathophysiological consequences of their responses remain unknown. Here, we report that cultured microglia sense low concentrations of the neurotoxicant methylmercury $\left(\mathrm{MeHg}^{\text {low }}\right)$ and provide neuroprotection against $\mathrm{MeHg}$, for which astrocytes are also required. When exposed to $\mathrm{MeHg}^{\text {low }}$, microglia exocytosed ATP via p38 MAPK- and vesicular nucleotide transporter (VNUT)-dependent mechanisms. Astrocytes responded to the microglia-derived ATP via P2 $_{1}$ receptors and released interleukin-6 (IL-6), thereby protecting neurons against $\mathrm{MeHg}^{\text {low }}$. These neuroprotective actions were also observed in organotypic hippocampal slices from wild-type mice, but not in slices prepared from VNUT knockout or $\mathrm{P}_{2} \mathrm{Y}_{1}$ receptor knockout mice. These findings suggest that microglia sense and respond to even non-hazardous toxicants such as $\mathrm{MeHg}^{\mathrm{low}}$ and change their phenotype into a neuroprotective one, for which astrocytic support is required.

M icroglia, the resident immune cells in the brain, continuously monitor the brain microenvironment ${ }^{1,2}$ and immediately respond to CNS disorders. Microglia are characterized by a very low threshold of activation, and their activation occurs within a few tens of minutes ${ }^{3}$. Microglial activation is a common feature of the early stage of CNS disorders ${ }^{4,5}$, during which they migrate toward the lesion, phagocytose debris and mediate inflammatory reactions ${ }^{6}$. The $\mathrm{P} 2$ receptor, a receptor for extracellular nucleotides, is highly expressed in microglia and participates in these reaction ${ }^{7,8}$. Extracellular ATP and other nucleotides are released or leak from injured cells under pathological conditions. For example, ATP released from apoptotic neurons contributes a 'find-me' signal' that activates microglial $\mathrm{P}^{9} \mathrm{Y}_{12}$ receptors and induces process extension ${ }^{8}$. In contrast, UDP functions as an 'eat-me' signal and triggers microglial phagocytosis via $\mathrm{P}_{2} \mathrm{Y}_{6}$ receptors?. In addition to the nucleotide-activated microglial function, microglia can release ATP ${ }^{10-12}$. Furthermore, microglia-derived ATP has recently been shown to activate the astrocytic $\mathrm{P}_{2} \mathrm{Y}_{1}$ receptor and trigger ATP release, which in turn regulates synaptic transmission ${ }^{13}$. $\mathrm{P}_{2} \mathrm{Y}_{1}$ receptor activation in astrocytes has been reported to induce neuroprotective effects against oxidative stress ${ }^{14}$, photothrombosis ${ }^{15}$, trauma $^{16}$ and neurotoxicants ${ }^{17}$. Although the physiological consequences of purinergic signal-mediated gliotransmission between microglia and astrocytes have begun to be identified, their neuroprotective roles are mostly unknown.

Methylmercury (MeHg), a well-known environmental pollutant, readily crosses the blood-brain barrier ${ }^{18,19}$ inducing serious neuronal damage ${ }^{20}$. Our previous report demonstrated that MeHg evoked ATP release from astrocytes, thereby activating their $\mathrm{P}_{2} \mathrm{Y}_{1}$ receptors, which was followed by interleukin-6 (IL-6) release ${ }^{17}$. Additionally, the ATP release from astrocytes required a relatively high concentration of $\mathrm{MeHg}(\geq 1 \mu \mathrm{M})$, whereas neuronal damage was observed at lower concentrations of $\mathrm{MeHg}(<1 \mu \mathrm{M})$, to which astrocytes showed no responses. Thus, other mechanisms appear to be required for neuroprotection against low concentrations of $\mathrm{MeHg}\left(\mathrm{MeHg}^{\text {low }}\right)$. It has been reported that microglia respond to lower concentrations of $\mathrm{MeHg}$ than do astrocytes in vitro ${ }^{21}$. In addition, long-term exposure of adult female Macaca fascicularis to a subclinical dose of $\mathrm{MeHg}$ 
(50 $\mu \mathrm{g} / \mathrm{kg}$ body weight/day) induced microglial activation but no changes in other brain cell types (i.e., neurons, astrocytes, oligodendrocytes, endothelia or pericytes $)^{22}$. Furthermore, it has been demonstrated that human microglia are activated in the absence of significant neuronal loss in the presence of a low concentration of $\mathrm{MeHg}$ (i.e., $<300 \mathrm{ppb})^{19}$, indicating potential neuroprotective roles of microglia. In fact, recent reports have shown microglia-mediated neuroprotective actions including neurotrophic support during brain development ${ }^{23}$, neuroprotection against NMDA-induced neurotoxicity ${ }^{24}$ and global brain ischemia ${ }^{25}$. Here we report that microglia can detect $\mathrm{MeHg}^{\text {low }}$, but their neuroprotective action against $\mathrm{MeHg}^{\text {low }}$ requires astrocytes. $\mathrm{MeHg}^{\text {low }}$ triggered VNUT-mediated microglial ATP release, which activated $\mathrm{P}_{2} \mathrm{Y}_{1}$ receptors in astrocytes thereby inducing IL- 6 production and neuroprotection.

\section{Results}

Astrocytes upregulate IL-6 expression in response to $\mathrm{MeHg}^{\text {high }}$ but not $\mathrm{MeHg}^{\text {low. }}$. Because we previously demonstrated that interleukin6 (IL-6) production from astrocytes was essential for neuroprotection against $\mathrm{MeHg}^{17}$, we first evaluated the concentration-dependency of MeHg-induced IL-6 expression in a rat primary astrocyte monoculture (Rt astrocytes). Although a high concentration of $\mathrm{MeHg}$ $\left(\mathrm{MeHg}^{\text {high }}, \geq 1 \mu \mathrm{M}\right)$ induced a significant increase in the amount of IL-6 production from the astrocyte monoculture, a low concentration of $\mathrm{MeHg}\left(\mathrm{MeHg}^{\text {low }}\right)$ (i.e., 0.01 or $0.1 \mu \mathrm{M}$ for $24 \mathrm{~h}$ ) did not increase the amount of IL-6 production from Rt astrocytes (Fig. 1a) in accordance with previous reports ${ }^{17,31}$. In contrast to astrocytes, neurons were more sensitive to $\mathrm{MeHg}$, and their viabilities decreased in the presence of even $\mathrm{MeHg}^{\text {low }}(0.1 \mu \mathrm{M})$, at which concentration astrocytes do not induce IL-6 production ${ }^{17,31}$. Because it has been reported that microglia respond to $\mathrm{MeHg}$ at concentrations too low to induce neuronal damage in vitro ${ }^{21}$, in macaques ${ }^{22}$ and in humans ${ }^{19}$, we next examined IL-6 production in a microglia monoculture. The results of ELISA analysis also showed no IL-6 release from rat $(\mathrm{Rt})$ microglia monocultures in the presence of any concentration of $\mathrm{MeHg}$ (Fig. 1b). Serum starvation for $24 \mathrm{~h}$ before $\mathrm{MeHg}$ treatment for IL-6 measurement did not affect microglial viability (Fig. S2a), so it is unlikely that the lack of IL-6 production from microglia is a result of cell damage owing to serum starvation. In contrast to these Rt microglial monocultures, mixed glial cultures of Rt primary astrocytes and microglia (at a ratio of $1: 5)$ released IL-6 in response to $\mathrm{MeHg}^{\text {low }}$ (Fig. 1c). In accordance with IL-6 production from the glial mixed culture in response to $\mathrm{MeHg}^{\text {low }}$, conditioned media from the Rt glial mixed culture (Microglia/Astrocytes-Conditioned Medium, MACM) exhibited neuroprotective effects against $\mathrm{MeHg}^{\text {low }}$ (Fig. 1d). MACM itself did not affect neuronal viability.

Microglia release ATP in response to $\mathrm{MeHg}^{\text {low }}$. Because we previously showed that extracellular ATP is essential for IL-6 production from astrocytes ${ }^{17}$, we then measured ATP release from individual monocultures or mixed glial cultures. Although our previous data showed that $\mathrm{MeHg}^{\text {high }}$ evoked ATP release from Rt astrocytes ${ }^{17}$, $\mathrm{MeHg}^{\text {low }}$ (i.e., 0.01 or $0.1 \mu \mathrm{M}, 3 \mathrm{~h}$ ) induced no ATP release from the astrocyte monoculture (Fig. 2a). In contrast, Rt microglia released ATP in response to $\mathrm{MeHg}^{\text {low }}$ but not to $\mathrm{MeHg}^{\text {high }}$ (1 or $3 \mu \mathrm{M}, 3 \mathrm{~h}$ )(Fig. 2b). At higher concentrations (i.e., $\geq 1 \mu \mathrm{M}$ ), microglia in monoculture exhibited necrotic cell death or decreased cell viability (Fig. S2b and S2c). The Rt mixed glial culture showed ATP release in response to both $\mathrm{MeHg}^{\text {low }}$ and $\mathrm{MeHg}^{\text {high }}$ (i.e., 0.1-3 $\mu \mathrm{M}, 3 \mathrm{~h}$ ) (Fig. 2c).

$\mathrm{MeHg}^{\text {low }}$ triggers ATP-mediated $\mathrm{Ca}^{2+}$ oscillations in astrocytes. Because astrocytes have been reported to show ATP-mediated intracellular $\mathrm{Ca}^{2+}$ oscillations (i.e., repetitive $\left[\mathrm{Ca}^{2+}\right] \mathrm{i}$ transients in a single astrocyte) in response to $\mathrm{MeHg}^{\text {high17 }}$, we examined whether microglia-derived ATP triggers astrocytic $\mathrm{Ca}^{2+}$ responses. We found that $\mathrm{MeHg}^{\text {low }}(0.1 \mu \mathrm{M}, 15$-min-treatment $)$ increased the frequency of $\mathrm{Ca}^{2+}$ oscillations in the Rt astrocytes in the mixed glial culture (Fig. 3a and 3b). The increased frequency of astrocytic $\mathrm{Ca}^{2+}$ oscillations in the mixed glial culture was maintained for at least $3 \mathrm{~h}$. In contrast to the mixed glial culture, in the Rt astrocyte monoculture, $\mathrm{MeHg}^{\text {low }}$ induced no changes in the frequencies of astrocytic $\mathrm{Ca}^{2+}$ oscillations (Fig. 3b). The increase in $\mathrm{MeHg}^{\text {low }}$ induced $\mathrm{Ca}^{2+}$ oscillations in the Rt astrocytes in the mixed glial (a) astrocytes

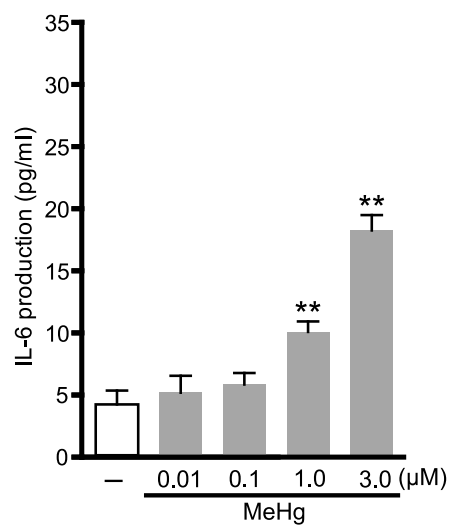

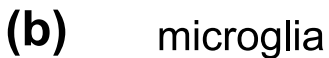

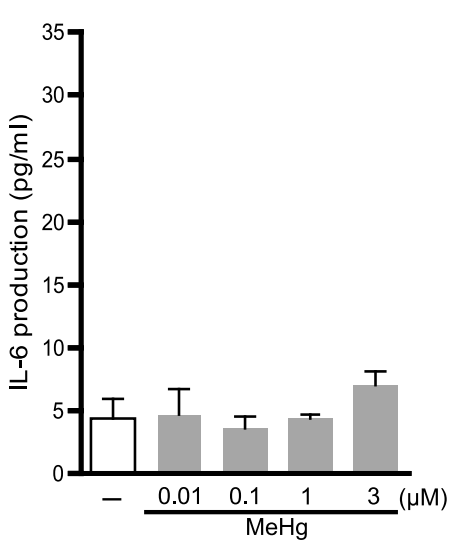

(c) microglia/astrocytes

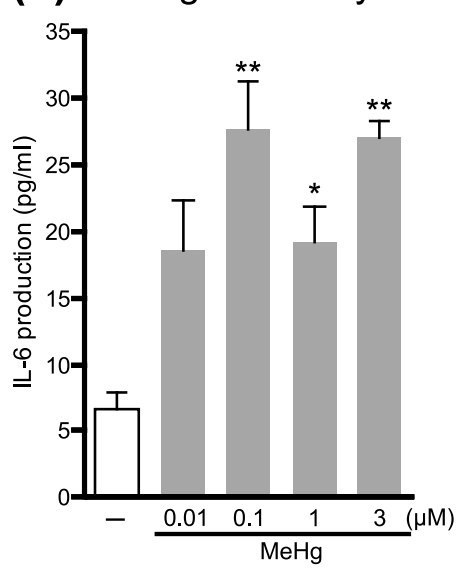

(d) neuron

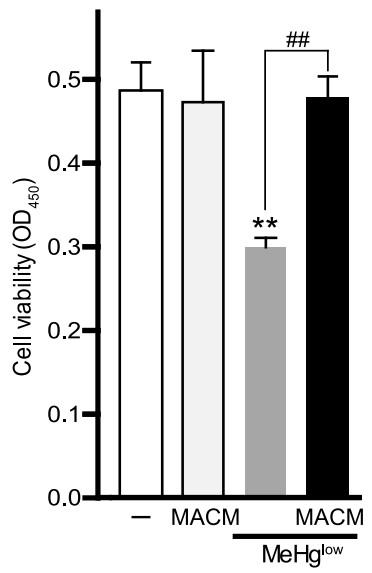

Figure 1 IL-6 release from astrocytes, microglia and mixed glial cultures. (a) ELISA analysis of MeHg-induced IL-6 release from astrocytes. $\mathrm{MeHg}^{\text {high }}(1$ or $3 \mu \mathrm{M}, 24 \mathrm{~h})$ increased in the amount of IL-6 release from Rt astrocytes but not by $\mathrm{MeHg}^{\text {low }}(0.01$ or $0.1 \mu \mathrm{M}, 24 \mathrm{~h})(\mathrm{n}=26, * * p<0.01$, one-way ANOVA followed by Fisher's LSD test). (b) Microglia released no IL-6 in response to MeHg. At no concentration did Rt microglia monocultures show significant IL-6 release ( $\mathrm{n}=12, p>0.05$, one-way ANOVA followed by Fisher's LSD test). (c) Rt microglia/astrocyte mixed cultures showed IL-6 release in response to both $\mathrm{MeHg}^{\text {low }}$ and $\mathrm{MeHg}^{\text {high }}(0.01-3 \mu \mathrm{M})\left(\mathrm{n}=8,{ }^{*} p<0.05,{ }^{*} p<0.01\right.$ vs. control, one-way ANOVA followed by Fisher's LSD test). For evaluating IL-6 production from glial cell cultures, the cells were serum starved for $24 \mathrm{~h}$ before MeHg stimulation. (d) Conditioned media from mixed glial cultures showed a neuroprotective effect on primary cortical neurons against MeHg. Reduced neuronal viability evoked by MeHglow $(0.1 \mu \mathrm{M}, 48 \mathrm{~h})$ was restored by MACM ( $\mathrm{n}=4-8,{ }^{* *} p<0.01$ vs. no treatment group; ${ }^{\# \#} p<0.01 \mathrm{vs.} \mathrm{MeHg \text {low }}$, one-way ANOVA followed by Fisher's LSD test). Without MeHg, MACM did not affect basal neuronal viability. Values are the means \pm SEM for all groups. 


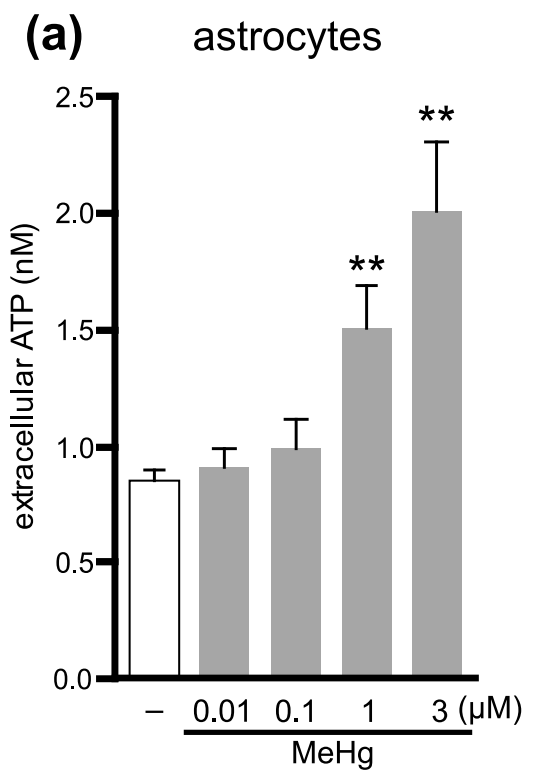

(b) microglia

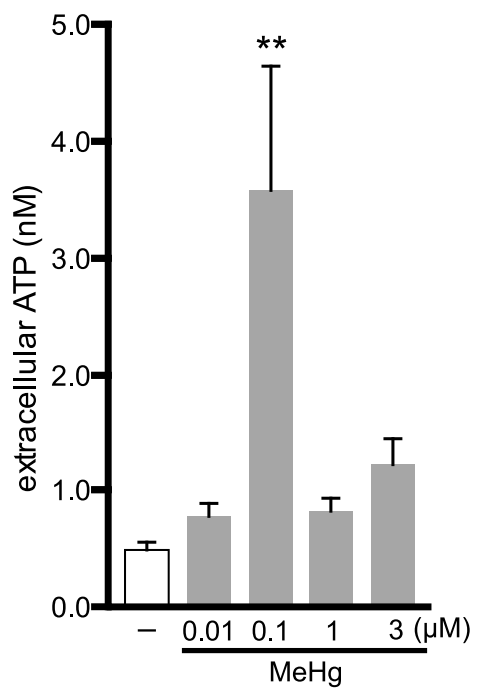

(c) microglia/astrocytes

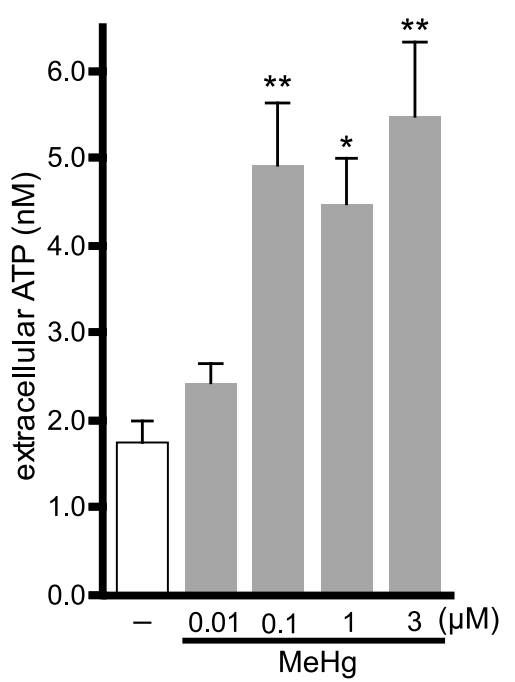

Figure $2 \mid$ ATP is released from astrocytes, microglia, and mixed glial cultures. (a) Rt astrocyte monocultures released ATP in response to MeHghigh ( 1 or $3 \mu \mathrm{M}$ for $3 \mathrm{~h}$ ) but not to $\mathrm{MeHg}^{\text {low }}$ (i.e., 0.01 or $0.1 \mu \mathrm{M}$ for $\left.3 \mathrm{~h}\right)\left(\mathrm{n}=15-24\right.$, ${ }^{* *} p<0.01$ vs. control, one-way ANOVA followed by Fisher's LSD test). (b) Microglia released ATP in response to a limited concentration window. $\mathrm{MeHg}^{\text {high }}$ did not induce ATP release from Rt microglia monocultures. At $0.1 \mu \mathrm{M}, \mathrm{MeHg}$ significantly increased the extracellular ATP level $(\mathrm{n}=24-28, * * p<0.01$ vs. control, one-way ANOVA followed by Fisher's LSD test). (c) Mixed glial cultures released ATP in response to both $\mathrm{MeHg}^{\text {low }}$ and $\mathrm{MeHg}^{\text {high }}$. Microglia/astrocyte mixed cultures released ATP in response to $0.1-3 \mu \mathrm{M}$ of $\mathrm{MeHg}$ (for $3 \mathrm{~h}$ ) ( $\mathrm{n}=10-16,{ }^{*} p<0.05,{ }^{*} p<0.01$ vs. control, one-way ANOVA followed by Fisher's LSD test). Glial cells were serum starved for $24 \mathrm{~h}$ before $\mathrm{MeHg}$ treatment. Values are the means \pm SEM for all groups.

culture was significantly suppressed by the broad $\mathrm{P} 2$ receptor antagonist suramin $(100 \mu \mathrm{M}, 30 \mathrm{~min}$ pretreatment) (Fig. 3b). Based on these data, we surmised that ATP released from microglia in response to $\mathrm{MeHg}^{\text {low }}$ evoked $\mathrm{Ca}^{2+}$ oscillations in astrocytes via $\mathrm{P} 2$ receptor activation.

Microglial ATP release is mediated by $\mathbf{p 3 8}$ activation. We then examined which intracellular signaling pathways mediate ATP release from Rt microglia. Because mitogen-activated protein kinases (MAPKs) are important for microglial activation ${ }^{32}$, we examined MAPK phosphorylation in a MeHg-treated Rt microglia monoculture. As shown in Figure $4 \mathrm{~b}$, neither ERK1/2 nor JNK showed enhanced phosphorylation (Fig. 4b), whereas p38 MAPK phosphorylation was increased in the presence of either 0.1 or $0.5 \mu \mathrm{M} \mathrm{MeHg}(2 \mathrm{~h}$ treatment) (Fig. 4a). Consistent with a previous report ${ }^{33}$, the Rt microglia exhibited necrotic cell death (a)

\section{microglia/astrocytes}

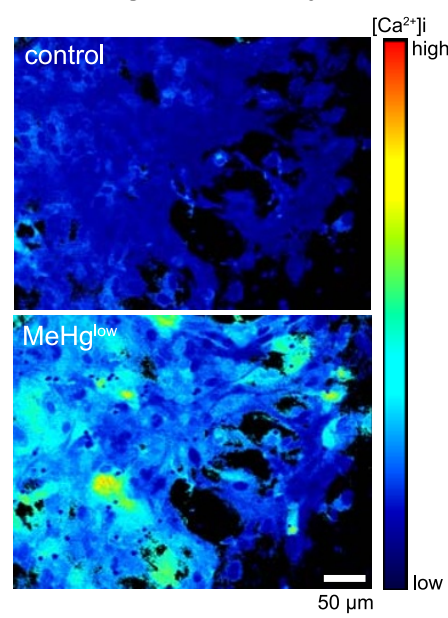

(b)
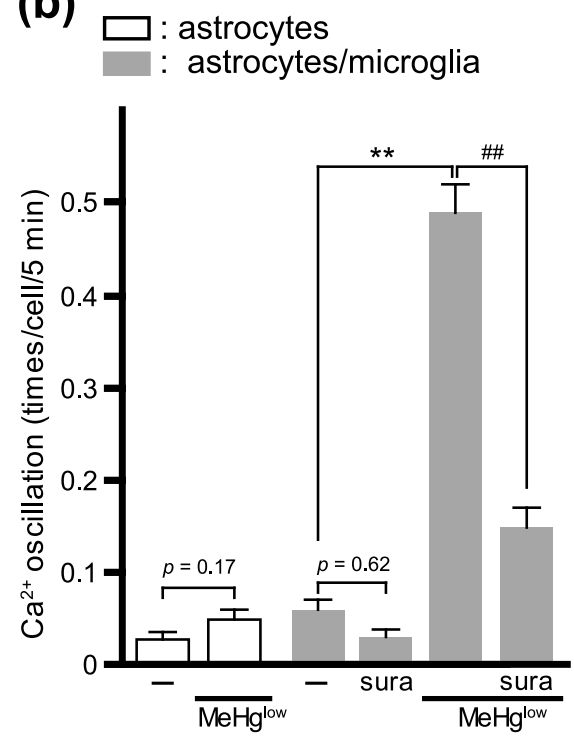

Figure $3 \mid \mathrm{MeHg}^{\mathrm{low}}$ increases astrocytic $\mathrm{Ca}^{2+}$ oscillations in mixed glial cultures via P2 receptor activation. (a) Typical Ca ${ }^{2+}$ responses in microglia/ astrocyte mixed cultures in response to $\mathrm{MeHg}^{\text {low }}(0.1 \mu \mathrm{M}, 15 \mathrm{~min}) . \mathrm{Ca}^{2+}$ images before (control) and after $(\mathrm{MeHg}) \mathrm{MeHg}{ }^{\text {low }}$ are shown. Scale bar: $50 \mu \mathrm{m}$. (b) The $\mathrm{MeHg}^{\text {low }}\left(0.1 \mu \mathrm{M}, 15\right.$ min treatment)-evoked increase in the frequencies of $\mathrm{Ca}^{2+}$ oscillations seen in astrocytes in the mixed glial cultures, which was suppressed by the $\mathrm{P} 2$ receptor antagonist suramin $(100 \mu \mathrm{M}, 30 \mathrm{~min}$ pretreatment $)(\mathrm{n}=110-240$, $* * p<0.01$ vs. astrocytes/microglia without $\mathrm{MeHg},{ }^{\# \#} p<0.01$ vs. astrocytes/microglia with $\mathrm{MeHg}^{\text {low }}$, one-way ANOVA followed by Fisher's LSD test). Astrocytes in the absence of microglia showed no $\mathrm{Ca}^{2+}$ responses to $\mathrm{MeHg}^{\text {low }}(0.1 \mu \mathrm{M}, 15 \mathrm{~min})$. Values are the means $\pm \mathrm{SEM}$ for $(\mathrm{b})$. 
(Fig. S2b) or decreased cell viability (Fig. S2c) in the presence of higher $\mathrm{MeHg}$ concentrations (i.e., $\geq 0.5 \mu \mathrm{M}$ ), resulting in reduced levels of $\beta$-actin (Fig. 4 b) and total p38 MAPK (Fig. 4a). To confirm p38 MAPK phosphorylation in Rt microglia, we next performed immunocytochemical analysis. Phosphorylated p38 MAPK signal was detected in $\mathrm{MeHg}^{\text {low }}(0.1 \mu \mathrm{M}, 2 \mathrm{~h})$-treated microglia in both the Rt microglial monoculture (Fig. 4c) and the Rt mixed glial culture (Fig. 4d), but was not observed in the absence of $\mathrm{MeHg}$ (Fig. 4c and 4d). No change in signal intensity for either phosphorylated ERK1/2 or JNK was observed in the presence of MeHg in either the monoculture or the mixed culture (Fig. $4 \mathrm{c}$ and $4 \mathrm{~d}$ ). We then examined whether activated p38 contributes to the $\mathrm{MeHg}$ evoked ATP release from Rt microglia. The ATP release induced by $\mathrm{MeHg}^{\text {low }}(0.1 \mu \mathrm{M}, 3 \mathrm{~h})$ from the Rt microglia monoculture was significantly suppressed in the presence of the p38 inhibitor SB203580 (10 $\mu \mathrm{M}, 15 \mathrm{~min}$ pretreatment) (Fig. 4e), indicating that p38 is essential for microglial ATP release. The $\mathrm{MeHg}^{\text {low }}(0.1 \mu \mathrm{M}$, $15 \mathrm{~min}$ )-induced increase in $\mathrm{Ca}^{2+}$ oscillations in astrocytes in the $\mathrm{Rt}$ mixed glial culture was also suppressed by SB203580 (Fig. 4f). Furthermore, $\mathrm{MeHg}^{\text {low }}(0.1 \mu \mathrm{M}, 24 \mathrm{~h})$-induced IL-6 production from the Rt mixed glial culture was also blocked by SB203580 (Fig. 4g). These data show that p38-mediated ATP release from microglia induces $\mathrm{P} 2$ receptor-mediated $\mathrm{Ca}^{2+}$ oscillations in and IL-6 production by astrocytes.

$\mathrm{MeHg}^{\text {low }}$ stimulates the exocytosis of ATP from microglia via a VNUT-mediated pathway(s). $\mathrm{MeHg}$ has been reported to both facilitate and suppress exocytosis ${ }^{17,34,35}$. In addition, we recently reported that microglia release ATP by exocytosis via a vesicular nucleotide transporter (VNUT)-mediated pathway(s) ${ }^{11}$; thus, we next investigated VNUT-mediated ATP release evoked by $\mathrm{MeHg}$. Botulinum toxin A (BoNT) (5 unit/ml, $24 \mathrm{~h}$ pretreatment), a toxin that cleaves SNAPs ${ }^{36,37}$ and thereby prevents exocytosis, significantly reduced $\mathrm{MeHg}^{\text {low }}(0.1 \mu \mathrm{M}, 3 \mathrm{~h})$-evoked ATP release from the Rt microglia monoculture (Fig. 5a). We then compared $\mathrm{MeHg}^{\text {low }}$ evoked ATP release from mouse (Ms) microglia monocultures prepared from WT and VNUT knockout mice (WT and VNUTKO microglia, respectively). $\mathrm{MeHg}^{\text {low }}$ evoked significant ATP release from WT microglia but not from a VNUTKO microglia monoculture (Fig. 5b). VNUTKO microglia exhibited similar morphology to WT microglia (Fig. S3a) and normal adhesion to culture dishes (Fig. S3b). $\mathrm{MeHg}^{\text {low }}(0.1 \mu \mathrm{M}, 24 \mathrm{~h})$ did not affect the number of adherent cells (Fig. S3c) or the viability of VNUTKO microglia (Fig. S3d), so it is unlikely that the lack of ATP release from VNUTKO microglia is due to damage caused by $\mathrm{MeHg}^{\text {low. In the }}$ Ms mixed glial culture, the $\mathrm{MeHg}^{\text {low }}(0.1 \mu \mathrm{M}, 3 \mathrm{~h})$-evoked ATP release was totally dependent on microglial VNUT (Fig. 5c). As shown in Fig. 3, $\mathrm{MeHg}^{\text {low }}$ evoked microglial ATP release, leading to subsequent astrocytic $\mathrm{Ca}^{2+}$ oscillations. $\mathrm{MeHg}^{\text {low }}(0.1 \mu \mathrm{M}, 15 \mathrm{~min}$ incubate) significantly increased $\mathrm{Ca}^{2+}$ oscillations in astrocytes in mixed cultures of WT microglia/WT astrocytes but not in mixed cultures of VNUTKO microglia/WT astrocytes (Fig. 5d). In accordance with ATP release and $\mathrm{Ca}^{2+}$ oscillations, the $\mathrm{MeHg}^{\text {low }}$ evoked IL-6 production from the mixed culture was also dependent on microglial VNUT (Fig. 5e). In the mixed culture, phase contrast images of VNUTKO microglia on WT astrocytes revealed them to be as normal as WT microglia, and the numbers of microglia on astrocytes were not different, regardless of VNUT expression in microglia (Fig. S3e). Similarly, the morphology and numbers of Iba1 (a microglial marker)-positive cells in the mixed culture did not change in response to $\mathrm{MeHg}^{\text {low }}(0.1 \mu \mathrm{M}, 24 \mathrm{~h})$ (Fig. S3f). Taken together, these findings suggest that the lack of ATP release, $\mathrm{Ca}^{2+}$ oscillations and IL-6 release in VNUTKO microglia/WT astrocytes is unlikely to be due to MeHg-induced cell death of VNUTKO microglia.

Activation of $\mathrm{P}^{2} \mathrm{Y}_{1}$ receptors in astrocytes is essential for IL-6 production from the mixed glial cultures. Microglial ATP acted on $\mathrm{P} 2$ receptors and then caused $\mathrm{Ca}^{2+}$ oscillations in astrocytes (Fig. 3). In our previous study, $\mathrm{MeHg}$-evoked $\mathrm{Ca}^{2+}$ signaling was mediated by $\mathrm{P} 2 \mathrm{Y}_{1}$ receptors in astrocytes ${ }^{17}$ and the $\mathrm{P} 2 \mathrm{Y}_{1}$ receptormediated $\mathrm{Ca}^{2+}$ oscillation was essential for IL-6 production. Similarly, the $\mathrm{MeHg}^{\text {low }}$-stimulated $\mathrm{Ca}^{2+}$ oscillations in astrocytes in the mixed glial culture were dependent on astrocytic $\mathrm{P}_{2} \mathrm{Y}_{1}$ receptors because $\mathrm{MeHg}^{\text {low }}$ significantly increased $\mathrm{Ca}^{2+}$ oscillations in astrocytes in the WT microglia/WT astrocyte culture, but not in astrocytes in the WT microglia/P2 $\mathrm{Y}_{1} \mathrm{KO}$ astrocyte culture (Fig. 6a). The $\mathrm{MeHg}^{\text {low }}$-evoked IL- 6 production in the glial mixed culture was also dependent on $\mathrm{P}_{2} \mathrm{Y}_{1}$ receptors in astrocytes (Fig. 6b).

Both VNUT and $\mathrm{P}_{2} \mathrm{Y}_{1}$ receptors are essential for an endogenous neuroprotective mechanism against $\mathrm{MeHg}^{\text {low }}$ in situ. To examine glial communication-mediated neuroprotection in situ, we employed an organotypic hippocampal culture. Neuronal cell death was assessed using propidium iodide (PI) $\left(5 \mu \mathrm{g} / \mathrm{ml}, 1 \mathrm{~h}\right.$ at $\left.37^{\circ} \mathrm{C}\right)$ incorporation, a widely used indicator of neuronal death in hippocampal slices ${ }^{38}$. In WT slices, $\mathrm{MeHg}^{\text {low }}(0.1 \mu \mathrm{M}, 48 \mathrm{~h})$ induced no increase in PI incorporation (Fig. 7a). $\mathrm{MeHg}^{\text {high }}(3 \mu \mathrm{M}, 48 \mathrm{~h}$ )induced PI-positive cells were co-localized with the neuronal marker NeuN, but not with the astrocyte marker glial fibrillary acidic protein (GFAP) or Iba1 (Fig. S4a-4c). Some NeuN signals in $\mathrm{MeHg}^{\text {high }}$-treated slices were co-localized with single-stranded DNA (ssDNA), a marker of apoptosis (Fig. S4d). When microglia or astrocytes were suppressed by minocycline or fluorocitrate (10 and $1 \mu \mathrm{M}$, respectively, $24 \mathrm{~h}$ pretreatment), $\mathrm{MeHg}^{\mathrm{low}_{\text {-induced }} \mathrm{PI}}$ incorporation was dramatically increased (Fig. 7b), indicating that both microglial and astrocytic activities were required for the endogenous neuroprotective mechanism against $\mathrm{MeHg}^{\text {low }}$. We then examined the role of $\mathrm{P}_{2} \mathrm{Y}_{1}$ receptor activity in this endogenous neuroprotection. The $\mathrm{P}_{2} \mathrm{Y}_{1}$ receptor antagonist MRS2179 $(10 \mu \mathrm{M}$, $24 \mathrm{~h}$ pretreatment) also increased PI incorporation. In addition, when extracellular IL- 6 was blocked by applying an IL- 6 antibody (200 pg/ml, simultaneous treatment), the PI signal was increased in the presence of $\mathrm{MeHg}^{\text {low }}$. In fact, $\mathrm{MeHg}^{\text {low }}$ evoked the release of ATP and the production of IL- 6 protein from WT slices $(3 \mathrm{~h}$ and $24 \mathrm{~h}$ treatment for ATP and IL-6, respectively) (Fig. 7c and 7d). These data indicate that glial activity, $\mathrm{P}_{2} \mathrm{Y}_{1}$ receptor activation and IL-6 production are essential for the endogenous neuroprotective mechanism against $\mathrm{MeHg}$ in WT slices. None out of minocycline, fluorocitrate, MRS2179 and the IL-6 blocking antibody affected basal PI incorporation in the absence of $\mathrm{MeHg}$ (data not shown). PI signals showed a characteristic spatial pattern that corresponded well to the distribution of pyramidal neurons from the CA1 region to the CA3 region (Fig. $7 \mathrm{a}$ and Fig. S4e).

To confirm the impact of VNUT-mediated ATP release on the neuroprotection observed in the in vitro study, we used hippocampal slices obtained from VNUT-KO mice (VNUTKO slices). We did not find any significant morphological abnormality or PI incorporation in the VNUTKO slices in the absence of MeHg. However, upon stimulation with $\mathrm{MeHg}^{\text {low }}(0.1 \mu \mathrm{M}, 48 \mathrm{~h})$, VNUTKO slices showed increased PI incorporation (Fig. 7e and 7f), which was restored by the exogenous application of ATP $(100 \mu \mathrm{M}, 30 \mathrm{~min}$ pretreatment) or recombinant IL-6 protein (100 pg/ml, simultaneous treatment). In addition, $\mathrm{MeHg}^{\text {low }}$ failed to stimulate the release of ATP or production of IL-6 in the VNUTKO slices (Fig. $7 \mathrm{~g}$ and 7h). Similar to the VNUTKO slices, the organotypic hippocampal slices from $\mathrm{P} 2 \mathrm{Y}_{1} \mathrm{R}$ $\mathrm{KO}$ mice ( $\mathrm{P} 2 \mathrm{Y}_{1} \mathrm{KO}$ slices) also showed pronounced increases in PI signals in response to $\mathrm{MeHg}^{\text {low }}(0.1 \mu \mathrm{M}, 48 \mathrm{~h}$ ) (Fig. $7 \mathrm{i}$ and $7 \mathrm{j}$ ). Without $\mathrm{MeHg}$, PI signals were hardly detected in the $\mathrm{P} 2 \mathrm{Y}_{1} \mathrm{KO}$ slices. Unlike the situation in VNUTKO slices, ATP did not rescue the $\mathrm{MeHg}^{\text {low }}$-induced neuronal damage in the $\mathrm{P} 2 \mathrm{Y}_{1} \mathrm{KO}$ slices, but recombinant IL-6 protein $(100 \mathrm{pg} / \mathrm{ml})$ did (Fig. $7 \mathrm{i}$ and $7 \mathrm{j})$, indicating that the release of ATP or IL-6 production is essential for the neuroprotection as an signal upstream or downstream of $\mathrm{P}_{2} \mathrm{Y}_{1}$ receptors, 
(a)

\section{microglia}

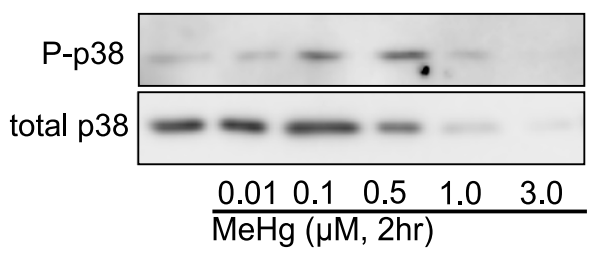

(b)

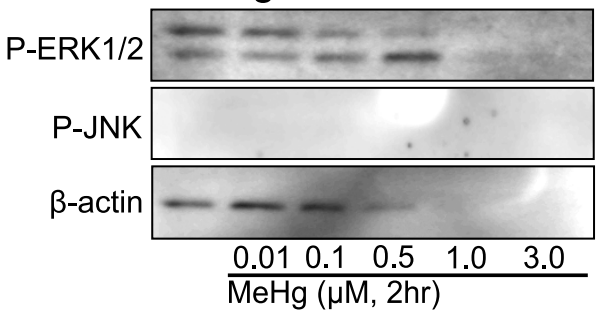

(c)
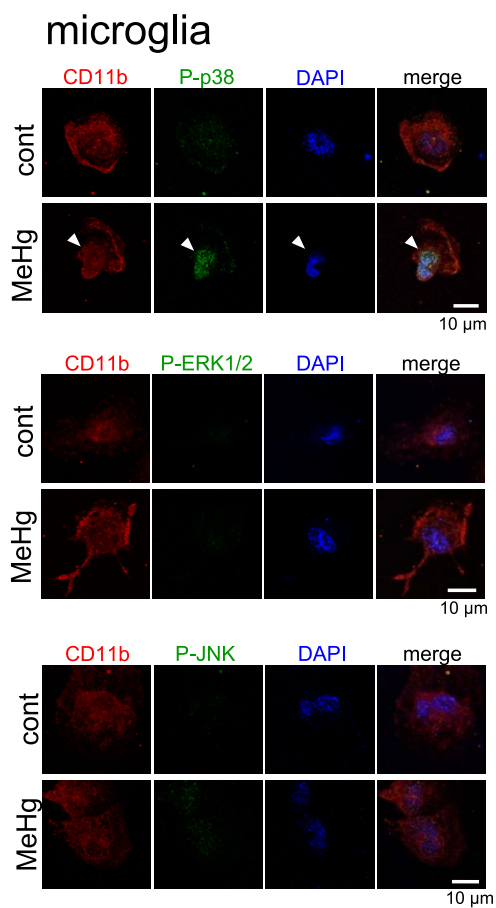

(d) microglia/astrocytes
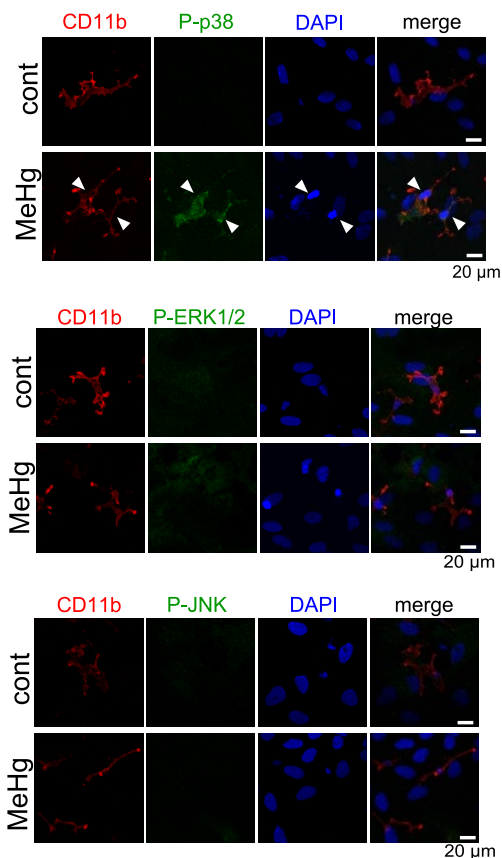

(e)

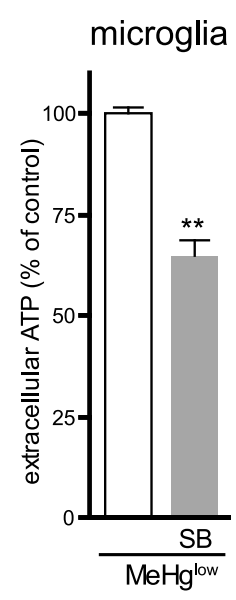

(f)

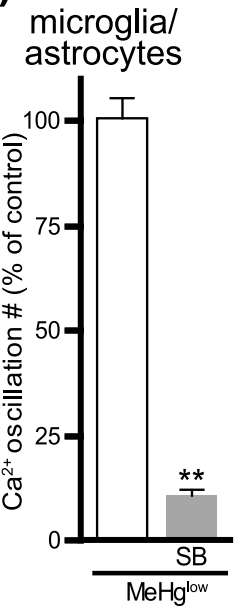

(g)

microglia/ astrocytes

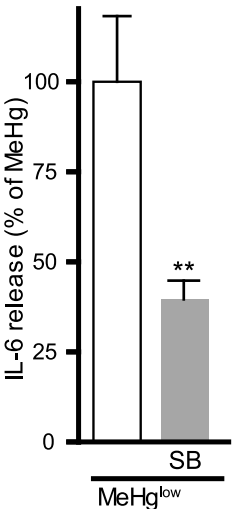

Figure $4 \mid$ Phosphorylation of p38 MAPK contributes to ATP release from microglia. (a) MeHg (2 h treatment) at 0.1 or $0.5 \mu \mathrm{M}$ evoked phosphorylation of p38 MAPK (P-p38 MAPK) in Rt microglia monocultures. (b) JNK MAPK was not phosphorylated by MeHg. P-ERK1/2 MAPK was rather decreased by $\mathrm{MeHg}$ at concentrations over $1.0 \mu \mathrm{M}$. The $\beta$-actin level was also decreased at concentrations of MeHg over $0.5 \mu \mathrm{M}$. Western blot data were cropped and the selected areas were shown here and full-length data are presented in Supplementary Figure 5. The gels have been run under the same experimental conditions. (c) Immunocytochemistry of phosphorylated MAPKs in a Rt microglia monoculture. P-p38 MAPK signal was increased (arrows) after MeHg ${ }^{\text {low }}$ treatment $(0.1 \mu \mathrm{M}, 2 \mathrm{~h})$. P-ERK1/2 or P-JNK MAPKs did not show enhanced signals in the presence of MeHg ${ }^{\text {low }}$. Scale bar: $10 \mu \mathrm{m}$. (d) Phosphorylation of MAPKs in a Rt mixed glial culture. The intensity of P-p38 MAPK signal was increased in microglia (arrows) by MeHglow. P-ERK1/ 2 MAPK signals were also enhanced but were localized in CD11b-negative cells. The P-JNK MAPK signal intensity was not changed. Scale bar: $20 \mu$ m. (e) ATP release is regulated by p38 MAPK. The $\mathrm{MeHg}^{\text {low }}(0.1 \mu \mathrm{M}, 3 \mathrm{~h})$-induced Rt microglial ATP release was significantly suppressed by a p38 MAPK

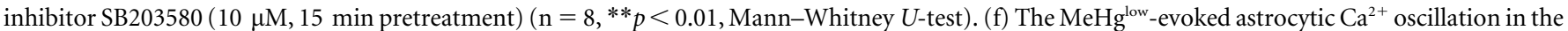
Rt glial mixed cultures is regulated by p38 MAPK. The increase in astrocytic $\mathrm{Ca}^{2+}$ oscillations induced by MeHg ${ }^{\text {low }}(0.1 \mu \mathrm{M}, 15$ min $)$ was reduced in the presence of SB203580 (10 $\mu \mathrm{M}, 15$ min pretreatment) $(\mathrm{n}=50, * * p<0.01$, Mann-Whitney $U$-test). (g) IL-6 production from glial mixed cultures is regulated by 38 MAPK. IL-6 production in $\mathrm{MeHg}^{\text {low }}(0.1 \mu \mathrm{M}, 24 \mathrm{~h})$-treated Rt mixed glial cultures was suppressed by SB203580 (10 $\mu \mathrm{M}, 15$ min pretreatment $)(\mathrm{n}=8, * * p<0.01$, Mann-Whitney $U$-test). Values are the means \pm SEM for $(\mathrm{e}-\mathrm{g})$. Microglia monocultures and glial mixed cultures were serum starved for $24 \mathrm{~h}$ before each experiment. 
(a) microglia

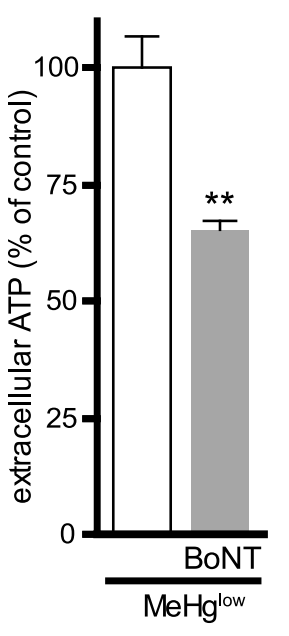

(b) microglia

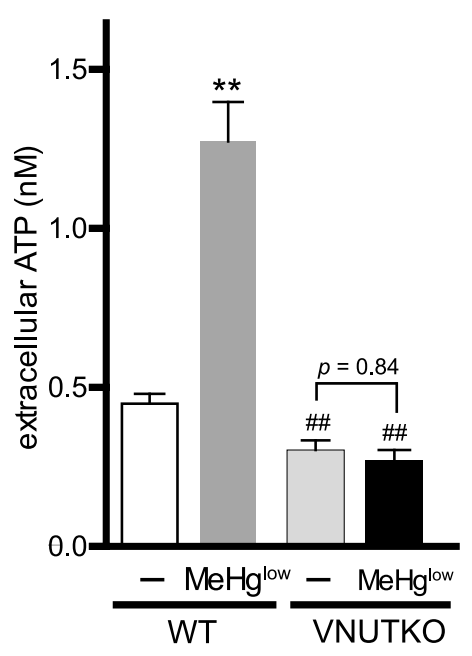

(c) microglia/astrocytes

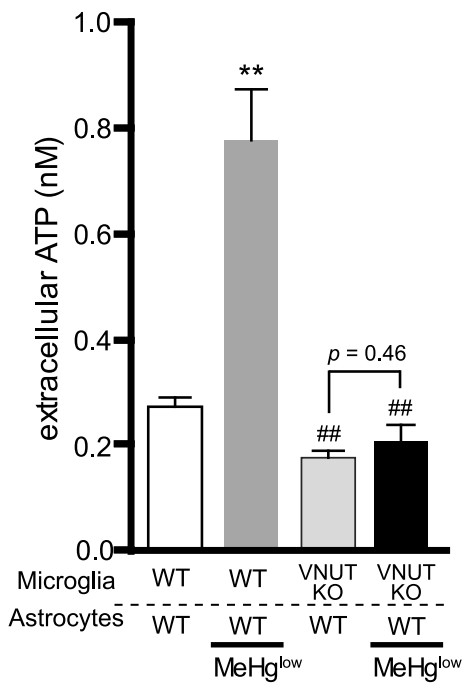

(d) microglia/astrocytes

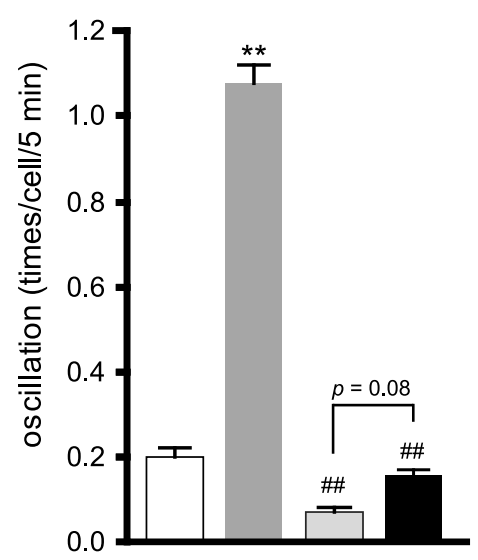

Microglia WT WT VNUT VNUT

Astrocytes ${ }^{-}$WT $\frac{\text { WT }}{\mathrm{MeHg}^{\text {low }}}$ WT $\frac{\text { WT }}{\mathrm{MeHg}^{\text {low }}}$ (e) microglia/astrocytes

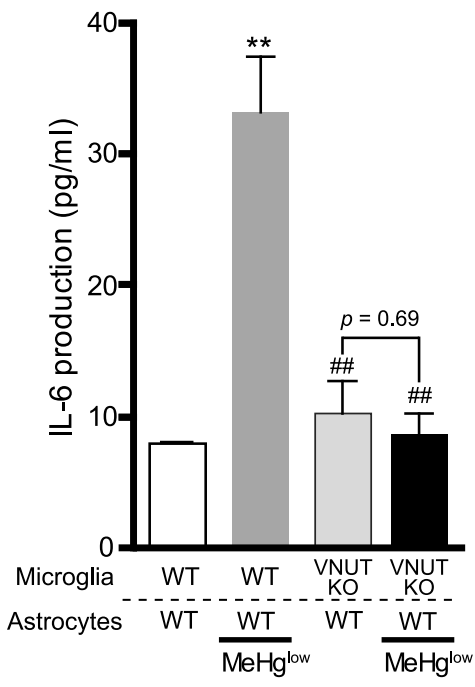

Figure 5 | VNUT-mediated ATP release from microglia is essential for $\mathrm{Ca}^{2+}$ signaling and IL-6 production from astrocytes in the mixed glial cultures. (a) Dependency of of the MeHg ${ }^{\text {low }}$-evoked ATP release on exocytosis. BoNT (5 units/ml, 24 h pretreatment) significantly suppressed the MeHglow induced ATP release from microglia $\left(\mathrm{n}=5,{ }^{* *} p<0.01\right.$, Mann-Whitney $U$-test). (b) Dependency of the MeHglow-evoked ATP release on VNUT. In contrast to ATP release from WT microglia, VNUTKO microglia showed no ATP release in response to $\operatorname{MeHg}^{\text {low }}(0.1 \mu \mathrm{M}, 3 \mathrm{~h})(\mathrm{n}=6-11$, ** $p<0.01 \mathrm{vs.}$ WT microglia without MeHg, ${ }^{\#} p<0.01$ vs. WT microglia with $\mathrm{MeHg}^{\text {low }}$, one-way ANOVA followed by Fisher's LSD test). (c) Microglial VNUT is essential for the $\mathrm{MeHg}^{\text {low }}$-evoked ATP release in Ms mixed glial cultures. $\mathrm{MeHg}^{\text {low }}(0.1 \mu \mathrm{M}, 3 \mathrm{~h})$ evoked ATP release in WT microglia/WT astrocyte mixed cultures but not in VNUTKO microglia/WT astrocyte cultures $\left(\mathrm{n}=8,{ }^{* *} p<0.01 \mathrm{vs.} \mathrm{WT} \mathrm{microglia/WT}\right.$ astrocytes without MeHg, ${ }^{\# \#} p<0.01$ vs. WT microglia/WT astrocytes with $\mathrm{MeHg}^{\text {low }}$, one-way ANOVA followed by Fisher's LSD test). (d) Microglial VNUT is indispensable for MeHg ${ }^{\text {low }}$-triggered $\mathrm{Ca}^{2+}$ oscillations in astrocytes in the Ms mixed glial cultures. $\mathrm{MeHg}^{\text {low }}(0.1 \mu \mathrm{M}, 15 \mathrm{~min})$ evoked a dramatic increase in the frequency of $\mathrm{Ca}^{2+}$ oscillations in astrocytes in WT microglia/WT astrocyte mixed cultures, but a small increase in VNUTKO microglia/WT astrocytes $(\mathrm{n}=98, * * p<0.01$ vs. WT microglia/WT astrocytes without MeHg, ${ }^{\# \#} p<0.01$ vs. WT microglia/WT astrocytes with $\mathrm{MeHg}^{\text {low }}$, one-way ANOVA followed by Fisher's LSD test). (e) Microglial VNUT-dependent IL-6 production in Ms mixed glial cultures. $\mathrm{MeHg}^{\text {low }}(0.1 \mu \mathrm{M}, 24 \mathrm{~h})$ evoked IL-6 production in WT microglia/WT astrocyte mixed cultures, but not in VNUTKO microglia/WT astrocytes $\left(\mathrm{n}=3,{ }^{* *} p<0.01 \mathrm{vs}\right.$. WT microglia/WT astrocytes without MeHg, ${ }^{\# \#} p<0.01 \mathrm{vs.}$ WT microglia/WT astrocytes with MeHglow, one-way ANOVA followed by Fisher's LSD test). Values are the means \pm SEM for all groups.

respectively, in situ. The finding that $\mathrm{MeHg}^{\text {low }}$ did not increase IL-6 production in $\mathrm{P}_{2} \mathrm{Y}_{1} \mathrm{KO}$ slices also supports this idea (Fig. 7k).

\section{Discussion}

The main findings in the present study are as follows. (i) Microglia detected $\mathrm{MeHg}^{\text {low }}$ and showed activation of p38 MAPK followed by
ATP release via a VNUT-dependent pathway. (ii) Although astrocytes did not sense $\mathrm{MeHg}^{\text {low }}$, they responded to the released ATP via $\mathrm{P}_{2} \mathrm{Y}_{1}$ receptors and produced IL-6, by which they protected neurons against $\mathrm{MeHg}$. (iii) These microglia-originated trilateral talks among microglia, astrocytes and neurons seen in the mixed cultures were mimicked in situ, and were essential for neuroprotection against $\mathrm{MeHg}^{\text {low }}$. 
(a) microglia/astrocytes

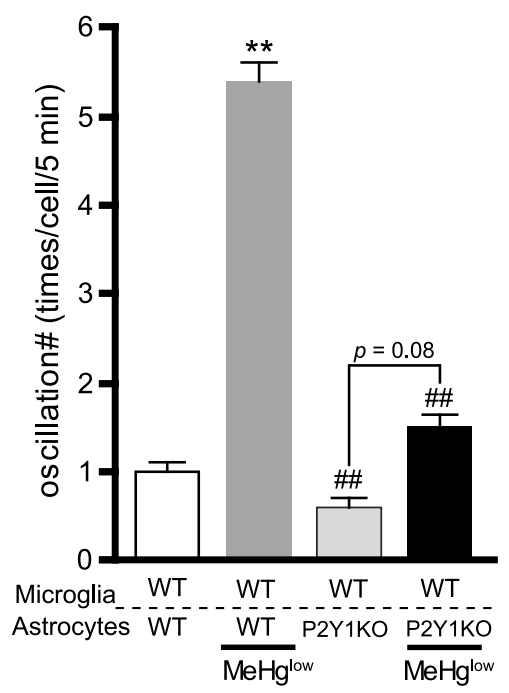

(b) microglia/astrocytes

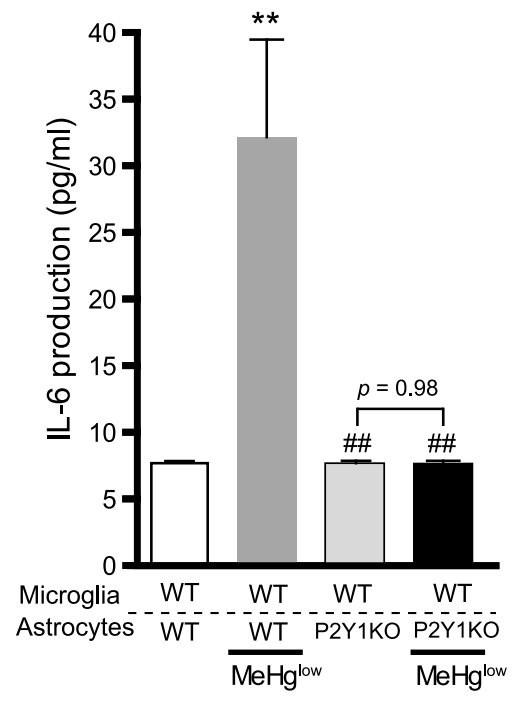

Figure 6 | Astrocytic P2Y 1 receptors are essential for IL-6 production from mixed glial cultures. (a) The enhancement of $\mathrm{Ca}^{2+}$ oscillations in astrocytes in the Ms mixed glial culture is mediated by astrocytic $\mathrm{P}_{2} \mathrm{Y}_{1}$ receptors. $\mathrm{MeHg}^{\text {low }}(0.1 \mu \mathrm{M}, 15$ min treatment $)$ dramatically increased the frequency of astrocytic $\mathrm{Ca}^{2+}$ oscillations in WT microglia/WT astrocyte cultures but not in co-cultures of WT microglia and P2Y ${ }_{1} \mathrm{KO}$ astrocytes (n $=98$, ** $p<0.01$ vs. WT microglia/WT astrocytes without MeHg, ${ }^{\# \#} p<0.01$ vs. WT microglia/WT astrocytes with $\mathrm{MeHg}{ }^{\text {low }}$, one-way ANOVA followed by Fisher's LSD test). (b) Activation of $\mathrm{P}_{2} \mathrm{Y}_{1}$ receptors in astrocytes is essential for IL-6 production in Ms mixed glial cultures. MeHg ${ }^{\text {low }}(0.1 \mu \mathrm{M}, 24 \mathrm{~h})$ increased IL-6 production in WT microglia/WT astrocytes but not in WT microglia/P2 $\mathrm{Y}_{1} \mathrm{KO}$ astrocytes $(\mathrm{n}=3, * * p<0.01$ vs. WT microglia/WT astrocytes without $\mathrm{MeHg},{ }^{\# \#} p<0.01$ vs. WT microglia/WT astrocytes with $\mathrm{MeHg}^{\text {low }}$, one-way ANOVA followed by Fisher's LSD test). Cells were serum starved for $24 \mathrm{~h}$ before $\mathrm{MeHg}$ treatment. Values are the means \pm SEM for all groups.

We have recently shown that astrocytes protect neurons against $\mathrm{MeHg}{ }^{\text {high }}$ by producing IL- $6^{17}$. In the present study, we focused on the effects induced by a much lower concentration of $\mathrm{MeHg}$, to which astrocytes cannot respond, and investigated the role of microglia, which are highly sensitive cells, in the brain microenvironment. There are many lines of evidence suggesting that microglia are activated even in a pre-symptomatic state or in the early stages of various diseases and after insults ${ }^{39,40}$. However, the physiological or pathophysiological consequences of such microglial activations in the presymptomatic state have remained largely unknown. With regard to $\mathrm{MeHg}$, it is reported that although a low $\mathrm{MeHg}$ concentration does not cause any sign of brain damage in intoxicated human individuals, microglia are already activated ${ }^{19}$, suggesting a potential role of microglia in the neuroprotection against $\mathrm{MeHg}$. In fact, recent reports have described the neuroprotective roles of microglia ${ }^{24,41,42}$. Here, we demonstrated that microglia function as a highly sensitive sensor of $\mathrm{MeHg}$ and reveal neuroprotective effects for which astrocytes are also required.

$\mathrm{MeHg}^{\text {low }}$ evoked ATP release but did not induce production of IL6 in a microglia monoculture (Figs. $1 \mathrm{~b}$ and 2b); by contrast, it increased neither ATP release nor IL- 6 production in an astrocyte monoculture (Figs. 1a and 2a), although $\mathrm{MeHg}^{\text {high }}$ could evoke both responses $^{17}$ (Figs 1a and 2a). Interestingly, $\mathrm{MeHg}$, even at a low concentration, could evoke both ATP release and IL- 6 production in the microglia/astrocyte mixed cultures (Figs. 1c and 2c). The simplest interpretation of these findings is that there is some form of communication between microglia and astrocytes. Eskes et al. previously showed that microglia evoke IL-6 production from astrocytes $^{31}$; however, the detailed molecular mechanisms underlying the communication between these cell types remain to be clarified. Our findings that pharmacological and genetic inhibition of both microglial ATP release and astrocytic $\mathrm{P}_{2} \mathrm{Y}_{1}$ receptors abolished these responses seen in the mixed glial cultures, suggest that microglia can sense $\mathrm{MeHg}^{\text {low }}$, which evoked release of ATP that functions as a paracrine signal and stimulates $\mathrm{P}_{2} \mathrm{Y}_{1}$ receptors in astrocytes to induce IL-6 upregulation. Although a previous report has shown that ATP induces production of IL-6 in microglia via $\mathrm{P}_{2} \mathrm{X}_{7}$ receptors ${ }^{43}$, $\mathrm{MeHg}^{\text {low }}$ did not induce IL-6 production from microglia (Fig. 1b). This discrepancy may be explained by the fact that the amount of released ATP in the present study was too low to activate $\mathrm{P}_{2} \mathrm{X}_{7}$ receptors because their activation requires a relatively high concentration of ATP (i.e., $>100 \mu \mathrm{M})^{43}$.

The findings that (1) $\mathrm{MeHg}^{\text {low }}$-evoked ATP release was significantly decreased by BoNT or in VNUTKO microglia (Figs. 5a and $5 b$ ), and (2) microglial ATP-induced $\mathrm{Ca}^{2+}$ oscillations in astrocytes were abolished in the mixed cultures of VNUTKO microglia/WT astrocytes (Fig. 5d), indicated that the microglial ATP release in response to $\mathrm{MeHg}^{\text {low }}$ should be mediated by exocytosis. Because a high concentration of ATP would be stored in exocytotic vesicles (e.g., $\sim 100 \mathrm{mM}$ in synaptic vesicles ${ }^{44}$ ), a locally released high concentration of ATP may be able to activate $\mathrm{P}_{2} \mathrm{X}_{7}$ receptors and induce IL- 6 production, but in our condition this was not the case. We recently demonstrated that microglia exocytosed ATP via VNUTdependent mechanisms, and this exocytosis was dramatically increased in inflammatory conditions ${ }^{11}$. Thus, if microglial ATP exocytosis is enhanced in some pathological conditions such as inflammation, the released ATP might function as an autocrine signal to activate $\mathrm{P} 2 \mathrm{X}_{7}$ receptors. However, the $\mathrm{P} 2 \mathrm{X}_{7}$ receptor antagonist brilliant blue $\mathrm{G}(1 \mu \mathrm{M})$ did not inhibit $\mathrm{MeHg}^{\text {low }}$-induced IL-6 production (data not shown). Therefore in the present experimental condition, instead of acting as an autocrine signal, microglial ATP seemed to function as a paracrine signal to activate $\mathrm{P} 2 \mathrm{Y}_{1}$ receptors in astrocytes.

We also found that p38 MAPK is involved in microglial ATP release (Fig. 4e). Many reports have demonstrated that p38 MAPK is a critical regulator of microglial activation ${ }^{45,46}$. Although p38 MAPK activation seems to be a common pathway for microglial activation, by which various microglial responses are regulated, to date its involvement in ATP exocytosis remains unknown. However, the activation of p38 MAPK is essential for the exocytosis of matrix 
(a)

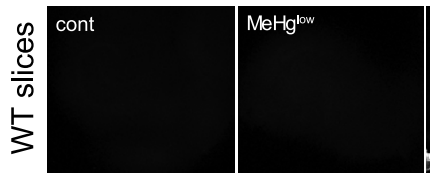

(b)

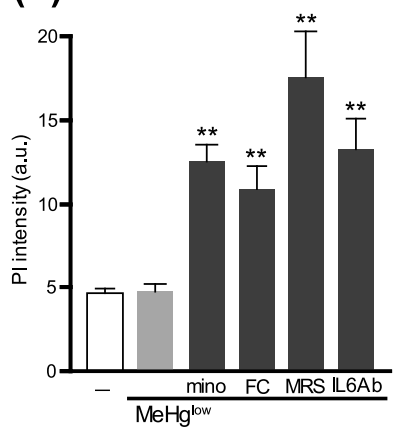

(e)
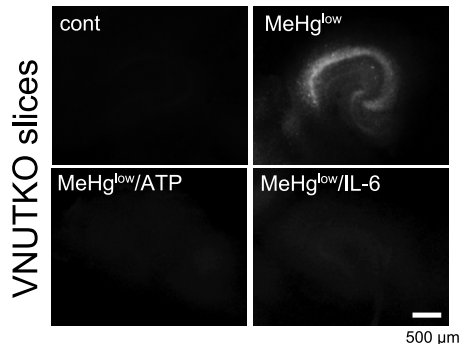

(i)

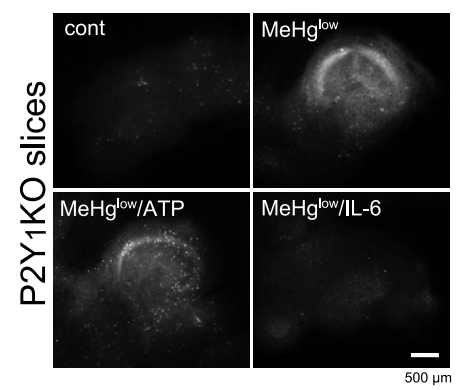

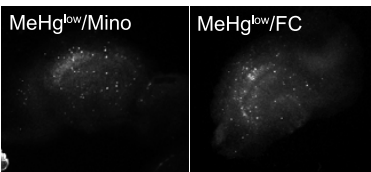

(c)

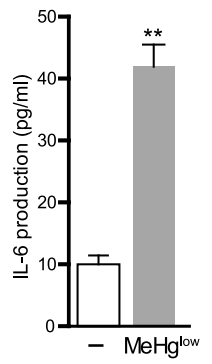

(f)

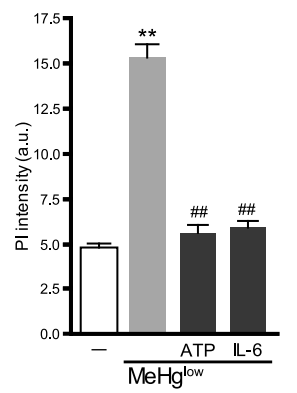

(j)

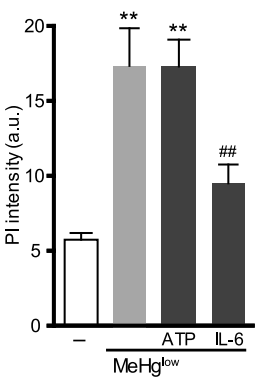

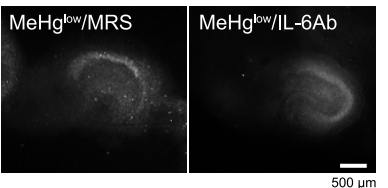

(d)

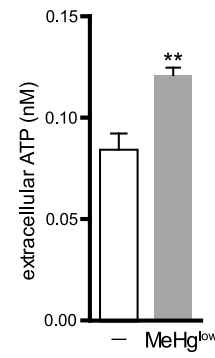

(g)

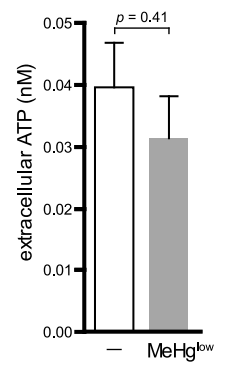

(h)

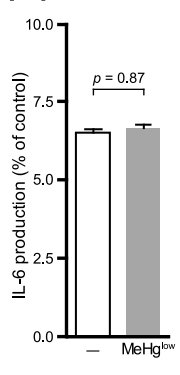

(k)

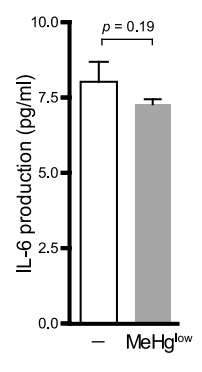

Figure 7 ATP-triggered trilateral communication pathways among microglia, astrocytes and neurons in organotypic hippocampal slice cultures. (a), (b) The endogenous neuroprotection is mediated by glial cells, $\mathrm{P}_{2} \mathrm{Y}_{1}$ receptors and IL-6. $\mathrm{MeHg}^{\text {low }}(0.1 \mu \mathrm{M}, 48 \mathrm{~h})$ did not cause an increase in PI incorporation in WT slices. The PI incorporation was increased by minocycline (mino, $10 \mu \mathrm{M}, 24 \mathrm{~h}$ pretreatment) or fluorocitrate (FC, $1 \mu \mathrm{M}, 24 \mathrm{~h}$ pretreatment), MRS2179 (MRS, $10 \mu \mathrm{M}, 24 \mathrm{~h}$ pretreatment) and an IL-6 blocking antibody (IL6Ab, $200 \mathrm{pg} / \mathrm{ml}$, simultaneous treatment) $(\mathrm{n}=8-11$, $* * p<0.01$ vs. control). (c) $\mathrm{MeHg}^{\text {low }}(0.1 \mu \mathrm{M}, 24 \mathrm{~h})$ increased IL-6 production from WT slices $(\mathrm{n}=4, * * p<0.01 \mathrm{vs.} \mathrm{control})$. (d) MeHg ${ }^{\text {low }}(0.1 \mu \mathrm{M}, 3 \mathrm{~h})$ increased ATP release from WT slices $\left(\mathrm{n}=5,{ }^{*} p<0.01\right.$ vs. control). (e), (f) $\mathrm{MeHg}^{\text {low }}(0.1 \mu \mathrm{M}, 48 \mathrm{~h})$ increased PI incorporation in VNUTKO slices, which was prevented by ATP $(100 \mu \mathrm{M}, 30$ min pretreatment $)$ or recombinant IL-6 protein $(100 \mathrm{pg} / \mathrm{ml}$, simultaneous treatment $)(\mathrm{n}=17-22, * * p<0.01$ vs. control, ${ }^{\# \#} p 0.01$ vs. $\left.\mathrm{MeHg}^{\text {low }}\right)$. (g) VNUTKO slices did not release ATP in response to $\mathrm{MeHg}^{\text {low }}(0.1 \mu \mathrm{M}, 3 \mathrm{~h})(\mathrm{n}=6, p=0.41)$. (h) MeHg ${ }^{\text {low }}$ $(0.1 \mu \mathrm{M}, 24 \mathrm{~h})$ did not induce any increase in IL-6 production from VNUTKO slices $(\mathrm{n}=4, p=0.87)$. (i), (j) Similar to the findings in VNUTKO slices, $\mathrm{MeHg}^{\text {low }}(0.1 \mu \mathrm{M}, 48 \mathrm{~h})$ increased PI incorporation in P2 $\mathrm{Y}_{1} \mathrm{KO}$ slices; however, unlike the results in VNUTKO slices, exogenously applied ATP (100 $\mu \mathrm{M}$, 30 min pretreatment) had no effect on $\mathrm{MeHg}^{\text {low }}$-increased PI incorporation. Recombinant IL-6 protein (100 pg/ml, simultaneous treatment) significantly reduced the PI signals $\left(\mathrm{n}=8-11,{ }^{* *} p<0.01\right.$ vs. control, ${ }^{\# *} p<0.01 \mathrm{vs}$. $\left.\mathrm{MeHg}^{\text {low }}\right)$. $(\mathrm{k}) \mathrm{MeHg}^{\text {low }}(0.1 \mu \mathrm{M}, 24 \mathrm{~h})$ did not induced IL-6 production from $\mathrm{P} 2 \mathrm{Y}_{1} \mathrm{KO}$ slices $(\mathrm{n}=4, p=0.19)$. Values are the mean \pm SEM for $(\mathrm{b}-\mathrm{d}),(\mathrm{f}-\mathrm{h}),(\mathrm{j})$ and $(\mathrm{k})$. Student's $t$-test and one-way ANOVA followed by Fisher's LSD test were used for comparisons of two and multiple groups, respectively.

metalloproteinase- 9 and myeloperoxidase in neutrophils ${ }^{47}$, and for the nucleotide-evoked exocytosis of elastase in neutrophils ${ }^{48}$. Thus, p38 MAPK may somehow affect the machinery of exocytosis. An initial mechanism of microglial activation by $\mathrm{MeHg}^{\text {low }}$ may be mediated by oxidative stress, because $\mathrm{MeHg}$ has been shown to induce oxidative stress ${ }^{49-53}$ and reactive oxygen species are well known to contribute to activation of both p38 MAPK $^{54-56}$ and microglia $^{57,58}$. Therefore, $\mathrm{MeHg}^{\text {low }}$ may change the redox state of microglia, 


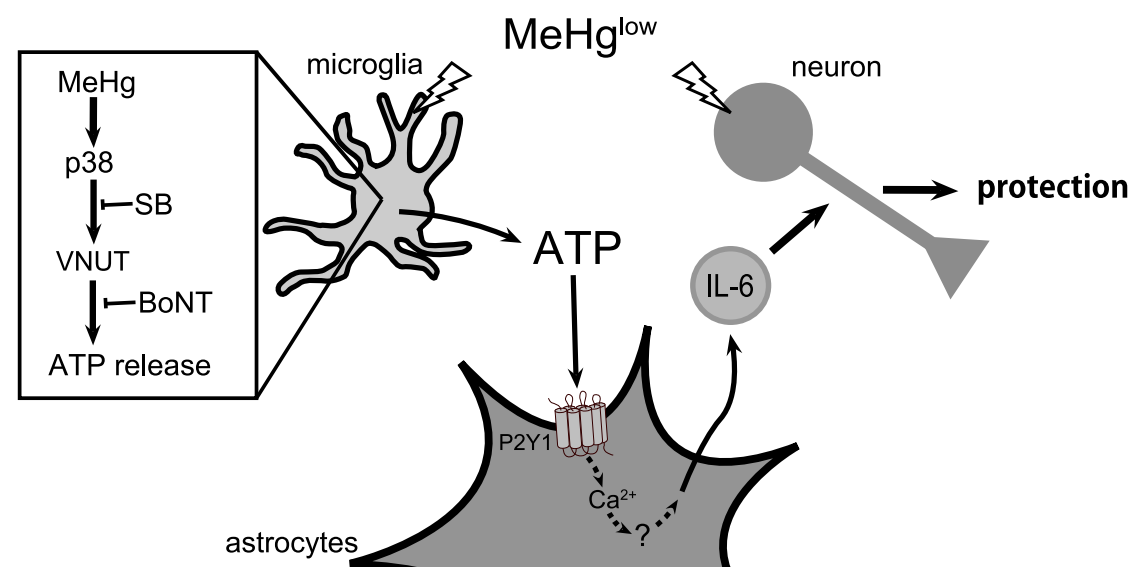

Figure $8 \mid$ Schematic diagram illustrating the communication pathways among microglia, astrocytes and neurons responsible for neuroprotection. When exposed to $\mathrm{MeHg}^{\text {low }}$, microglia sense $\mathrm{MeHg}^{\text {low }}$ and activation of $\mathrm{p} 38$ MAPK occurs. This is followed by VNUT-dependent ATP exocytosis. The microglia-derived ATP in turn activates $\mathrm{P}_{2} \mathrm{Y}_{1}$ receptors and induces $\mathrm{Ca}^{2+}$ oscillations in astrocytes. The activation of $\mathrm{P} 2 \mathrm{Y}_{1}$ receptors induces IL-6 release from astrocytes, thereby leading to neuroprotection against $\mathrm{MeHg}$.

thereby causing their activation. Although the molecular mechanisms underlying the microglial sensing of $\mathrm{MeHg}^{\text {low }}$ and the subsequent activation of p38 MAPK and ATP exocytosis have not been fully clarified, we clearly showed that microglia sense $\mathrm{MeHg}^{\text {low }}$ and exocytose ATP via p38 MAPK- and VNUT-dependent mechanisms, which is especially important because these microglial events initiate the subsequent trilateral communication among microglia, astrocytes and neurons.

Finally, we demonstrated that the $\mathrm{MeHg}^{\text {low }}$-evoked microglia-toastrocyte communication by ATP seen in the mixed glial cultures was mimicked in situ using organotypic hippocampal slice cultures (Fig. 7). In the slice culture experiments, we rather focused on the relationship between this form of communication and neuronal damage. Again, (1) $\mathrm{MeHg}^{\text {low }}$ evoked microglial ATP exocytosis; and (2) this microglial ATP activated $\mathrm{P}_{2} \mathrm{Y}_{1}$ receptors leading to the upregulation of IL- 6 in the astrocytes of mixed cultures. Similarly, (1) $\mathrm{MeHg}^{\text {low }}$ evoked ATP release in WT slices, which was abolished by genetic inhibition of VNUT; and (2) $\mathrm{MeHg}^{\text {low }}$ evoked IL-6 production, which was abolished by genetic inhibition of either VNUT or $\mathrm{P}_{2} \mathrm{Y}_{1}$ receptors (Fig. 7). More importantly, these genetic and pharmacological inhibitions resulted in neuronal damage induced by $\mathrm{MeHg}^{\text {low }}$, which was prevented by the addition of recombinant IL6. Regarding the mechanism of IL-6-mediated neuroprotection, we and other groups have shown that both upregulation of adenosine $A_{1}$ receptors and suppression of glutamate-mediated excitotoxicity are involved $^{17,59,60}$. These results suggest that an endogenous neuroprotective mechanism(s) against brain insults is formed by the communication network among microglia, astrocytes and neurons. Microglia are especially important in this mechanism because their sensing and responses can be a trigger of a subsequent chain of responses.

As summarized in Fig. 8, we demonstrated the following findings. Microglia, a highly sensitive microenvironmental sensor, senses $\mathrm{MeHg}^{\text {low }}$ and responds via exoytosis of ATP, for which p38 MAPK and VNUT are essential. Although astrocytes do not respond to $\mathrm{MeHg}^{\text {low }}$, they receive microglial ATP through $\mathrm{P}_{2} \mathrm{Y}_{1}$ receptors, produce IL-6 and thereby provide neuroprotection against $\mathrm{MeHg}^{\text {low }}$. Microglia respond to non-hazardous insults or change their phenotypes even in the presymptomatic state of diseases. Such early responses in microglia might be key events in protecting neurons, and should be studied further toward clarifying the causes of brain diseases.

\section{Methods}

Detailed methods are provided in the Supplementary information.
Animals. All animals used in this study were obtained, housed, cared for and used in accordance with the "Guiding Principles in the Care and Use of Animals in the Field of Physiologic Sciences" published by the Physiologic Society of Japan and with the previous approval of the Animal Care Committee of Yamanashi University (Chuo, Yamanashi, Japan). Wistar rats and C57BL/6 mice (17-day-old fetal) were obtained from Japan SLC (Shizuoka, Japan). P2Y 1 receptor knockout mice (C57BL/6 background) were developed as previously reported ${ }^{26}$. Vesicular nucleotide transporter knockout (VNUTKO) mice were generated by the standard gene disruption procedure. For genotyping polymerase chain reaction (PCR), the primers used were as follows: WT forward, 5'-CTA TGT GTA GCC CTG GAT GG-3'; WT reverse, 5'-GTG TAC CCT TCG GGG AAA GT-3'; VNUTKO forward (corresponding to a partial sequence inside PGK promoter that drives the Neo gene), 5'-CTT GTG TTT GGG ATC CTG GT-3'; and VNUTKO reverse, 5'-GGG AGG ATT GGG AAG ACA AT-3'. They were backcrossed onto a C57BL/6 background and used.

Cell culture. Glial monocultures were prepared as previously reported ${ }^{7,27}$. Briefly, cerebral cortices dissected from newborn Wistar rats or C57BL/6 mice were digested in $0.1 \%$ trypsin-EDTA and the cells were cultured in a flask. For microglia monoculture, cells were collected by gentle shaking of the flask. For astrocyte monoculture, the flask was subjected to $24 \mathrm{~h}$ of continuous shaking. For the mixed glial culture, microglia were added to a confluently cultured astrocyte culture. Glial cells were maintained in DMEM supplemented with $10 \%$ fetal bovine serum (FBS), 10 units $/ \mathrm{ml}$ penicillin, and $10 \mu \mathrm{g} / \mathrm{ml}$ streptomycin under conditions of $10 \% \mathrm{CO}_{2}$ at $37^{\circ} \mathrm{C}$.

Neuronal culture was prepared as previously described ${ }^{28}$. Cerebral cortices dissected from 17-day-old fetal mice were digested in 50 units/ml papain. Neurons were maintained in neuronal culture medium (DMEM supplemented with 5\% horse serum, 5\% FBS, 10 units $/ \mathrm{ml}$ penicillin, and $10 \mu \mathrm{g} / \mathrm{ml}$ streptomycin) under conditions of $10 \% \mathrm{CO}_{2}$ at $37^{\circ} \mathrm{C}$ and were treated with cytosine $\beta$-D-arabinofuranoside (ara-C, $10 \mu \mathrm{M})$ two days after plating. The culture medium was changed twice a week and neurons were used 14 days after plating.

Assay of cell survival. Cell survival was estimated by WST-1 assay using a cell counting kit (Dojindo, Kumamoto, Japan), which determines cell viability based on the extent of cleavage of a soluble tetrazolium salt WST-1 by mitochondrial dehydrogenases. Briefly, cells were incubated for $1 \mathrm{~h}$ with the WST-1 reagent at a $1: 10$ dilution at $37^{\circ} \mathrm{C}$. The absorbance of media was then measured using a microplate reader at $450 \mathrm{~nm}$ with $650 \mathrm{~nm}$ as a reference wavelength.

Organotypic slice cultures. Organotypic hippocampal slice cultures were made as previously reported ${ }^{29,30}$. Briefly, hippocampi from 5- to 7-day-old mice were dissected, placed in ice-cold HBSS containing $6 \mathrm{mg} / \mathrm{ml}$ of D-(+)-glucose for $15 \mathrm{~min}$, and transverse slices $(300 \mu \mathrm{m})$ were obtained using a McIlwain tissue chopper (Mickle Laboratory Engineering Co. Ltd., Gomshall, UK). Six slices were placed on a Millicell-CM culture plate insert (PICMORG50, Millipore, Billerica, MA, USA) and maintained in slice culture medium (50\% MEM, 25\% Hanks BSS, 25\% heatinactivated horse serum, $2 \mathrm{mM}$ L-glutamine, $6.5 \mathrm{~g} / \mathrm{l}$ glucose, $100 \mathrm{units} / \mathrm{ml}$ penicillin and $100 \mu \mathrm{g} / \mathrm{ml}$ streptomycin) under conditions of $5 \% \mathrm{CO}_{2}$ at $37^{\circ} \mathrm{C}$ and used for experiments 7 days after incubation with medium change every few days. Neuronal cell death was evaluated by propidium iodide (PI) incorporation and PI fluorescence images were obtained using a Keyence BV-8000 fluorescence microscope (Tokyo, Japan) at an exposure time of $0.5 \mathrm{~s}$. The PI intensity was estimated using Image J software (http://rsbweb.nih.gov/ij/). 
Quantitative RT-PCR. Total RNA was isolated and purified from cultured cells using RNeasy kits (Qiagen, Hilden, Germany) according to the manufacturer's instructions. Before RNA isolation, cells were serum-starved for $24 \mathrm{~h}$. Reverse transcription (RT)PCR was performed using a one step PrimeScript ${ }^{\circledR}$ RT-PCR Kit (Takara Bio Inc., Shiga, Japan) according to the manufacturer's protocol. The reaction mix contained $40 \mathrm{ng}$ of total RNA, $200 \mathrm{nM}$ primers, $100 \mathrm{nM}$ TaqMan probe, Takara EX Taq ${ }^{\circledR} \mathrm{HS}$ and PrimeScript ${ }^{\mathrm{TM}}$ RT enzyme Mix. RT-PCR amplification and real-time detection were performed using an Applied Biosystems 7500 Real-Time PCR System (Applied Biosystems, Foster City, CA, USA). Reverse transcription was performed at $42^{\circ} \mathrm{C}$ for $5 \mathrm{~min}$ followed by inactivation at $95^{\circ} \mathrm{C}$ for $10 \mathrm{~s}$. The temperature profile consisted of 40 cycles of denaturation at $95^{\circ} \mathrm{C}$ for $5 \mathrm{~s}$, and annealing/extension at $60^{\circ} \mathrm{C}$ for $34 \mathrm{~s}$. The sequences of the primers and probe for rat IL- 6 were as follows: TaqMan probe, $5^{\prime}$-CAGAATTGCCATTGCACAACTCTTTTCTCA-3'; forward primer, 5'-CAGTGCATCATCGCTGTTCA-3'; and reverse primer, 5' -CATATGTTCTCAGGGAGATCTTGGA-3'. The primers and TaqMan probe for GAPDH were obtained from Rodent GAPDH Control Reagents (Applied Biosystems). Mouse IL-6 expression was estimated using the probe set (Mm0046190-m1) from Applied Biosystems.

Enzyme-linked immunosorbent assay of IL-6. MeHg-induced IL-6 production from astrocytes, microglia, astrocytes/microglia mixed culture or organotypic hippocampal slice cultures was measured using a Quantikine ${ }^{\circledR}$ rat or mouse IL-6 immunoassay kit (R\&D Systems, MN, USA). The assay was performed according to the manufacturer's instructions. All standards and samples were measured using a microplate reader at a wavelength of $450 \mathrm{~nm}$

$\mathrm{Ca}^{2+}$-imaging. Changes in intracellular $\mathrm{Ca}^{2+}$ were measured using the fura 2 method with minor modification $\mathrm{s}^{28}$. In brief, the culture medium was replaced with balanced salt solution (BSS) of the following composition (in mM): $\mathrm{NaCl} 150, \mathrm{KCl} 5.0, \mathrm{CaCl}_{2}$ $1.8, \mathrm{MgCl}_{2} 1.2$, HEPES 25, and D-glucose 10 ( $\mathrm{pH}$ 7.4). Cells were loaded with fura 2 by incubation with $10 \mu \mathrm{M}$ fura 2-acetoxymethyl ester (fura 2-AM) at room temperature in BSS for $45 \mathrm{~min}$. After loading, the samples were mounted on a microscope (ECLIPSE TE2000-U, Nikon, Tokyo, Japan) equipped with a 75-W xenon lamp and band-pass filters of 340 and $380 \mathrm{~nm}$ wavelengths for measurement of the $\mathrm{Ca}^{2+}$. dependent signals (F340 and F380 nm). Image data were recorded using a CCD camera (ORCA-ER, Hamamatsu Photonics, Shizuoka, Japan). For evaluation, we used the F340/F380 ratio. To estimate the frequency of $\mathrm{Ca}^{2+}$ oscillations in astrocytes, we compared the numbers of $\mathrm{Ca}^{2+}$ oscillations in a single astrocyte within 5 minutes.

Immunocytochemistry and immunohistochemistry. Cells cultured in $\mu$-dish (Ibidi $\mathrm{GmbH}$, Munich, Germany) or slices were serum starved for $24 \mathrm{~h}$ followed by $\mathrm{MeHg}^{\text {low }}$ treatment $(2 \mathrm{~h})$ and fixed with $4 \%$ PFA for $30 \mathrm{~min}$ at room temperature. After permeabilization/blocking in PBS with $0.3 \%$ Triton X-100 (PBST) containing 3\% goat serum for $1 \mathrm{~h}$ at room temperature, samples were incubated with the primary antibodies (CD11b, GFAP, Iba1, NeuN, phospho-p38, phospho-ERK1/2, phosphoJNK, and ssDNA at $1: 1000$ ) in Can Get Signal A (TOYOBO, Osaka, Japan) for $24 \mathrm{~h}$ at $4{ }^{\circ} \mathrm{C}$. Then, the cells were further incubated with Alexa dye-conjugated secondary antibodies (at $1: 1000)$ for $1 \mathrm{~h}$ at room temperature. Fluorescence images were obtained using a laser scanning confocal microscope FV-1000 (Olympus, Tokyo, Japan). For nuclear staining, 4',6-Diamidino-2-phenylindole, dihydrochloride (DAPI) $(1 \mu \mathrm{g} / \mathrm{ml})$ was used.

Measurement of extracellular ATP. The extracellular ATP concentrations of $\mathrm{MeHg}$ treated cells or slices were determined using an ATP bioluminescence assay kit CLS II (Roche Applied Science, Mannheim, Germany). Cells or slices were serum starved for $24 \mathrm{~h}$ followed by incubation for $3 \mathrm{~h}$ with $\mathrm{MeHg}(0.01,0.1,1$ or $3 \mu \mathrm{M})$ in serum-free medium, and the supernatants were collected and immediately boiled at $95^{\circ} \mathrm{C}$ for $5 \mathrm{~min}$. Equal volumes of luciferin/luciferase reagents and samples $(100 \mu \mathrm{l} \mathrm{each})$ were mixed a few times by gentle pipetting. All standards and samples were measured using a Lumat LB9501 tube luminometer (Berthold, Wildbad, Germany). The ATP concentrations were calculated from the intensities of a series of standard ATP. For glial cells, samples were collected from 24 -well plates (i.e., $1 \times 10^{5}$ cells in astrocyte monocultures, $6 \times 10^{4}$ cells in microglia monocultures, or mixed cultures of $1 \times 10^{5}$ astrocytes and $2 \times 10^{4}$ microglia). For hippocampal slices, samples were collected from 12-well plates (i.e., one slice/well)

Western blotting. Cells for western blotting were serum starved for $24 \mathrm{~h}$ before $\mathrm{MeHg}$ treatment $(2 \mathrm{~h})$. Cell lysates were electrophoresed by $10 \%$ SDS-PAGE gels and transferred to PVDF membranes. The membranes were blocked for $1 \mathrm{~h}$ in Trisbuffered saline containing $0.1 \%$ Tween- 20 and 5\% BSA at room temperature and were incubated with primary antibodies $(1: 1000)$ overnight at $4{ }^{\circ} \mathrm{C}$. Membranes were then incubated with horseradish peroxidase-conjugated secondary antibodies $(1: 20,000)$ for $1 \mathrm{~h}$ at room temperature. Protein bands were visualized by rinsing the membrane with SuperSignal West Pico Chemiluminescence Substrate (Thermo Scientific, PA, USA). Images were obtained using a LAS-4000 imaging system (Fujifilm, Tokyo, Japan). Full-length data of each blot are shown in Figure S5.

Statistics. Data are expressed as means \pm SEM. The Student's $t$-test or MannWhitney $U$-test was used for comparisons of two groups. For multiple comparisons, one way parametric ANOVA followed by Fisher's least significant difference (LSD) test was used. Differences were considered to be significant when the $P$ value was less than 0.05
1. Tremblay, M. E. et al. The role of microglia in the healthy brain. J Neurosci 31, 16064-16069 (2011).

2. Nimmerjahn, A., Kirchhoff, F. \& Helmchen, F. Resting microglial cells are highly dynamic surveillants of brain parenchyma in vivo. Science 308, 1314-1318 (2005).

3. Davalos, D. et al. ATP mediates rapid microglial response to local brain injury in vivo. Nat Neurosci 8, 752-758 (2005).

4. Ouchi, Y. et al. Microglial activation and dopamine terminal loss in early Parkinson's disease. Ann Neurol 57, 168-175 (2005).

5. Kingwell, K. Neurodegenerative disease: Microglia in early disease stages. Nat Rev Neurol 8, 475 (2012).

6. Kettenmann, H., Hanisch, U. K., Noda, M. \& Verkhratsky, A. Physiology of microglia. Physiol Rev 91, 461-553 (2011).

7. Koizumi, S. et al. UDP acting at P2Y6 receptors is a mediator of microglial phagocytosis. Nature 446, 1091-1095 (2007).

8. Haynes, S. E. et al. The P2Y12 receptor regulates microglial activation by extracellular nucleotides. Nat Neurosci 9, 1512-1519 (2006).

9. Chekeni, F. B. et al. Pannexin 1 channels mediate 'find-me' signal release and membrane permeability during apoptosis. Nature 467, 863-867 (2010).

10. Liu, G. J., Kalous, A., Werry, E. L. \& Bennett, M. R. Purine release from spinal cord microglia after elevation of calcium by glutamate. Mol Pharmacol 70, 851-859 (2006).

11. Imura, Y. et al. Microglia release ATP by exocytosis. Glia 61, 1320-1330 (2013).

12. Dou, Y. et al. Microglial migration mediated by ATP-induced ATP release from lysosomes. Cell Res 22, 1022-1033 (2012).

13. Pascual, O., Ben Achour, S., Rostaing, P., Triller, A. \& Bessis, A. Microglia activation triggers astrocyte-mediated modulation of excitatory neurotransmission. Proc Natl Acad Sci U S A 109, E197-205 (2012).

14. Fujita, T., Tozaki-Saitoh, H. \& Inoue, K. P2Y1 receptor signaling enhances neuroprotection by astrocytes against oxidative stress via IL-6 release in hippocampal cultures. Glia 57, 244-257 (2009).

15. Zheng, W. et al. Purinergic receptor stimulation reduces cytotoxic edema and brain infarcts in mouse induced by photothrombosis by energizing glial mitochondria. PLoS One 5, el4401 (2010).

16. Talley Watts, L. et al. Purinergic $2 \mathrm{Y} 1$ receptor stimulation decreases cerebral edema and reactive gliosis in a traumatic brain injury model. J Neurotrauma $\mathbf{3 0}$, 55-66 (2013).

17. Noguchi, Y. et al. Astrocytes protect neurons against methylmercury via ATP/ P2Y(1) receptor-mediated pathways in astrocytes. PLoS One 8, e57898 (2013).

18. Clarkson, T. W. The toxicology of mercury. Crit Rev Clin Lab Sci 34, 369-403 (1997).

19. Lapham, L. W. et al. An analysis of autopsy brain tissue from infants prenatally exposed to methymercury. Neurotoxicology 16, 689-704 (1995).

20. Clarkson, T. W., Magos, L. \& Myers, G. J. The toxicology of mercury--current exposures and clinical manifestations. N Engl J Med 349, 1731-1737 (2003).

21. Monnet-Tschudi, F., Zurich, M. G. \& Honegger, P. Comparison of the developmental effects of two mercury compounds on glial cells and neurons in aggregate cultures of rat telencephalon. Brain Res 741, 52-59 (1996).

22. Charleston, J. S. et al. Increases in the number of reactive glia in the visual cortex of Macaca fascicularis following subclinical long-term methyl mercury exposure. Toxicol Appl Pharmacol 129, 196-206 (1994).

23. Ueno, M. et al. Layer V cortical neurons require microglial support for survival during postnatal development. Nat Neurosci 16, 543-551 (2013).

24 . Vinet, J. et al. Neuroprotective function for ramified microglia in hippocampal excitotoxicity. J Neuroinflammation 9, 27 (2012).

25. Imai, H. et al. Development of a fast method for quantitative measurement of hyperpolarized 129Xe dynamics in mouse brain. NMR Biomed 25, 210-217 (2012).

26. Leon, C. et al. Defective platelet aggregation and increased resistance to thrombosis in purinergic P2Y(1) receptor-null mice. J Clin Invest 104, 1731-1737 (1999).

27. Shinozaki, Y. et al. Cytoprotection against oxidative stress-induced damage of astrocytes by extracellular ATP via P2Y1 receptors. Glia 49, 288-300 (2005).

28. Koizumi, S., Fujishita, K., Tsuda, M., Shigemoto-Mogami, Y. \& Inoue, K. Dynamic inhibition of excitatory synaptic transmission by astrocyte-derived ATP in hippocampal cultures. Proc Natl Acad Sci U S A 100, 11023-11028 (2003).

29. Shinozaki, Y. et al. Retinoic acids acting through retinoid receptors protect hippocampal neurons from oxygen-glucose deprivation-mediated cell death by inhibition of c-jun-N-terminal kinase and p38 mitogen-activated protein kinase. Neuroscience 147, 153-163 (2007)

30. Gogolla, N., Galimberti, I., DePaola, V. \& Caroni, P. Preparation of organotypic hippocampal slice cultures for long-term live imaging. Nat Protoc 1, 1165-1171 (2006).

31. Eskes, C., Honegger, P., Juillerat-Jeanneret, L. \& Monnet-Tschudi, F. Microglial reaction induced by noncytotoxic methylmercury treatment leads to neuroprotection via interactions with astrocytes and IL-6 release. Glia 37, 43-52 (2002).

32. Tikka, T., Fiebich, B. L., Goldsteins, G., Keinanen, R. \& Koistinaho, J. Minocycline, a tetracycline derivative, is neuroprotective against excitotoxicity by inhibiting activation and proliferation of microglia. J Neurosci 21, 2580-2588 (2001).

33. Nishioku, T. et al. Involvement of caspase 3-like protease in methylmercuryinduced apoptosis of primary cultured rat cerebral microglia. Brain Res $\mathbf{8 7 1}$, 160-164 (2000) 
34. Tiernan, C. T., Edwin, E. A., Goudreau, J. L., Atchison, W. D. \& Lookingland, K. J. The role of de novo catecholamine synthesis in mediating methylmercuryinduced vesicular dopamine release from rat pheochromocytoma (PC12) cells. Toxicol Sci 133, 125-132 (2013).

35. Graevskaya, E. E., Yasutake, A., Aramaki, R. \& Rubin, A. B. Effect of methylmercury on histamine release from rat mast cells. Arch Toxicol 77, 17-21 (2003).

36. Blasi, J. et al. Botulinum neurotoxin A selectively cleaves the synaptic protein SNAP-25. Nature 365, 160-163 (1993).

37. Binz, T. et al. Proteolysis of SNAP-25 by types E and A botulinal neurotoxins. J Biol Chem 269, 1617-1620 (1994).

38. Macklis, J. D. \& Madison, R. D. Progressive incorporation of propidium iodide in cultured mouse neurons correlates with declining electrophysiological status: a fluorescence scale of membrane integrity. J Neurosci Methods 31, 43-46 (1990).

39. Tai, Y. F. et al. Microglial activation in presymptomatic Huntington's disease gene carriers. Brain 130, 1759-1766 (2007).

40. Sanagi, T. et al. Involvement of activated microglia in increased vulnerability of motoneurons after facial nerve avulsion in presymptomatic amyotrophic lateral sclerosis model rats. Glia 60, 782-793 (2012).

41. Neumann, J. et al. Microglia provide neuroprotection after ischemia. FASEB J 20 , 714-716 (2006).

42. Mitrasinovic, O. M. et al. Microglia overexpressing the macrophage colonystimulating factor receptor are neuroprotective in a microglial-hippocampal organotypic coculture system. J Neurosci 25, 4442-4451 (2005).

43. Shigemoto-Mogami, Y. et al. Mechanisms underlying extracellular ATP-evoked interleukin-6 release in mouse microglial cell line, MG-5. J Neurochem 78, 1339-1349 (2001).

44. Burnstock, G. Physiology and pathophysiology of purinergic neurotransmission. Physiol Rev 87, 659-797 (2007).

45. Tsuda, M., Mizokoshi, A., Shigemoto-Mogami, Y., Koizumi, S. \& Inoue, K Activation of p38 mitogen-activated protein kinase in spinal hyperactive microglia contributes to pain hypersensitivity following peripheral nerve injury. Glia 45, 89-95 (2004).

46. Jin, S. X., Zhuang, Z. Y., Woolf, C. J. \& Ji, R. R. p38 mitogen-activated protein kinase is activated after a spinal nerve ligation in spinal cord microglia and dorsal root ganglion neurons and contributes to the generation of neuropathic pain. J Neurosci 23, 4017-4022 (2003).

47. Ehrenfeld, P. et al. Kinin B1 receptor activation turns on exocytosis of matrix metalloprotease-9 and myeloperoxidase in human neutrophils: involvement of mitogen-activated protein kinase family. J Leukoc Biol 86, 1179-1189 (2009).

48. Meshki, J., Tuluc, F., Bredetean, O., Ding, Z. \& Kunapuli, S. P. Molecular mechanism of nucleotide-induced primary granule release in human neutrophils: role for the P2Y2 receptor. Am J Physiol Cell Physiol 286, C264-271 (2004).

49. Yee, S. \& Choi, B. H. Oxidative stress in neurotoxic effects of methylmercury poisoning. Neurotoxicology 17, 17-26 (1996).

50. Mundy, W. R. \& Freudenrich, T. M. Sensitivity of immature neurons in culture to metal-induced changes in reactive oxygen species and intracellular free calcium. Neurotoxicology 21, 1135-1144 (2000).

51. Gasso, S. et al. Antioxidant compounds and $\mathrm{Ca}(2+)$ pathway blockers differentially protect against methylmercury and mercuric chloride neurotoxicity. J Neurosci Res 66, 135-145 (2001).

52. Ali, S. F., LeBel, C. P. \& Bondy, S. C. Reactive oxygen species formation as a biomarker of methylmercury and trimethyltin neurotoxicity. Neurotoxicology 13, 637-648 (1992).
53. Ni, M. et al. Methylmercury induces acute oxidative stress, altering Nrf2 protein level in primary microglial cells. Toxicol Sci 116, 590-603 (2010).

54. Zhuang, S., Demirs, J. T. \& Kochevar, I. E. p38 mitogen-activated protein kinase mediates bid cleavage, mitochondrial dysfunction, and caspase- 3 activation during apoptosis induced by singlet oxygen but not by hydrogen peroxide. J Biol Chem 275, 25939-25948 (2000).

55. Kurata, S. Selective activation of p 38 MAPK cascade and mitotic arrest caused by low level oxidative stress. J Biol Chem 275, 23413-23416 (2000).

56. Ushio-Fukai, M., Alexander, R. W., Akers, M. \& Griendling, K. K. p38 Mitogenactivated protein kinase is a critical component of the redox-sensitive signaling pathways activated by angiotensin II. Role in vascular smooth muscle cell hypertrophy. J Biol Chem 273, 15022-15029 (1998).

57. Qin, L. et al. Interactive role of the toll-like receptor 4 and reactive oxygen species in LPS-induced microglia activation. Glia 52, 78-84 (2005).

58. Block, M. L., Zecca, L. \& Hong, J. S. Microglia-mediated neurotoxicity: uncovering the molecular mechanisms. Nat Rev Neurosci 8, 57-69 (2007).

59. Biber, K. et al. Interleukin-6 upregulates neuronal adenosine A1 receptors: implications for neuromodulation and neuroprotection. Neuropsychopharmacology 33, 2237-2250 (2008).

60. Biber, K., Lubrich, B., Fiebich, B. L., Boddeke, H. W. \& van Calker, D. Interleukin6 enhances expression of adenosine $\mathrm{A}(1)$ receptor $\mathrm{mRNA}$ and signaling in cultured rat cortical astrocytes and brain slices. Neuropsychopharmacology 24, 86-96 (2001).

\section{Acknowledgments}

We thank Dr. Shigetomi, Dr. Shibata, Dr. Imura, Ms. Hirayama, Mr. Morizawa, Mr. Komatsu, Ms. Kobayashi, and Mr. Taguchi for fruitful discussion. This work was supported by a grant for the Study (Group) of the Health Effects of Heavy Metals Organized by the Ministry of the Environment, Japan (to S.K.), and KAKENHI on Innovative Areas (25116512 \& 25117003)(to S.K.) and on Challenging Exploratory Research (25670622)(to S.K.).

\section{Author contributions}

S.K. designed the experiments and supervised the studies. Y.S. performed the experiments Y.S. and S.K. prepared the manuscript. M.N., K.I. and Y.M. made the VNUTKO mice. C.G. made $\mathrm{P}_{2} \mathrm{Y}_{1} \mathrm{KO}$ mice. All authors reviewed the manuscript.

\section{Additional information}

Supplementary information accompanies this paper at http://www.nature.com/ scientificreports

Competing financial interests: The authors declare no competing financial interests.

How to cite this article: Shinozaki, Y. et al. Microglia trigger astrocyte-mediated neuroprotection via purinergic gliotransmission. Sci. Rep. 4, 4329; DOI:10.1038/srep04329 (2014)

cc) (i) (2) This work is licensed under a Creative Commons AttributionNonCommercial-ShareAlike 3.0 Unported license. To view a copy of this license, visit http://creativecommons.org/licenses/by-nc-sa/3.0 